\title{
THESIS
}

\section{PERCEIVED IMPACT AND EXPERIENCE OF LONG-TERM YOGA INVOLVEMENT FOR PEOPLE WITH CHRONIC PAIN}

\author{
Submitted by \\ Caroline M. Rose \\ Department of Occupational Therapy
}

In partial fulfillment of the requirements

For the Degree of Master of Science

Colorado State University

Fort Collins, Colorado

Summer 2018

Master's Committee:

Advisor: Arlene A. Schmid

Karen E. Atler

Jennifer D. Portz 
Copyright by Caroline M. Rose 2018

All Rights Reserved 


\begin{abstract}
PERCEIVED IMPACT AND EXPERIENCE OF LONG-TERM YOGA INVOLVEMENT FOR PEOPLE WITH CHRONIC PAIN
\end{abstract}

The aim of this study was to investigate the perceived impact and experience of longterm involvement in a community-based group yoga class for people with chronic pain. Eleven participants, who previously completed an 8-week yoga intervention and continued attending yoga at a community pain clinic for 2 years, took part in the study. A mixed methods approach was employed. Two-year follow-ups of the Canadian Occupational Performance Measure (COPM) were collected and compared to baseline COPM scores to measure change in perceived occupational performance and satisfaction. Individual qualitative interviews were conducted to explore participants' perceived impact and experience of long-term yoga involvement. COPM data were analyzed using Wilcoxon sign ranked non-parametric tests and qualitative interviews were analyzed using an inductive approach. COPM performance and satisfaction scores significantly improved between baseline and follow up after 2 years of yoga. Three main themes emerged from the qualitative interviews: 1) Occupational shift from "living" to "existing," 2) The change process is "progressive," and 3) Yoga is "a positive thing I do in my life." Long-term involvement in community-based group yoga may improve and sustain occupational health and well-being. Therefore, occupational therapists may consider yoga as a tool to promote occupational health in people with chronic pain. 


\section{ACKNOWLEDGEMENTS}

This research experience would not have been possible without my supportive team, and I owe them great thanks. Special thanks goes to Dr. Arlene Schmid, my thesis advisor, for providing structure, support, encouragement, wisdom, and laughter every step of the way. To Dr. Karen Atler, for guiding me through the qualitative process and graciously reminding me to enjoy the journey. To Dr. Jennifer Portz, for offering insights and critical feedback throughout the process. To my husband, Nick, for steadily believing in me and comforting me during the difficult moments. To Ally Andrews, my yoga research companion, for the many hours she spent coding my interviews and for sharing the struggles and accomplishments of this thesis student experience with me. I would also like to thank my friends and family for understanding the magnitude of this project and loving me through the stressful and celebratory times. Most especially, my warmest thanks to the participants at the Pain Clinic, who shared their inspirational stories and expanded my understanding of life with pain. 


\section{DEDICATION}

Lastly, I would like to dedicate this thesis to the people in my life who have shown me and continue to show me the power and magic of yoga. To honor these individuals, their initials were used as the pseudonyms for the participants in this study. 


\section{TABLE OF CONTENTS}

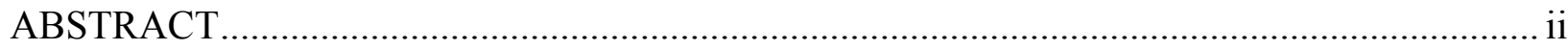

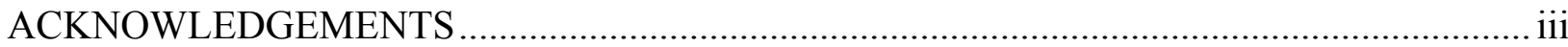

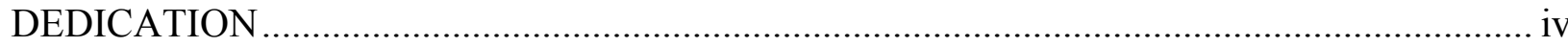

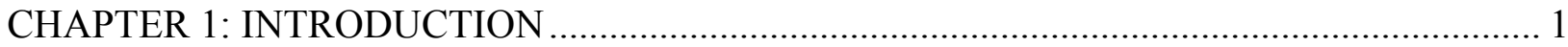

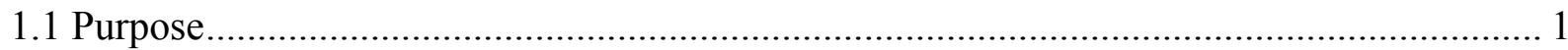

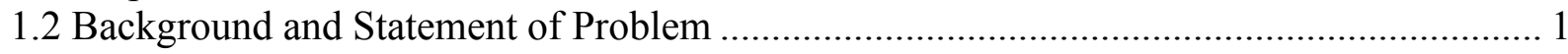

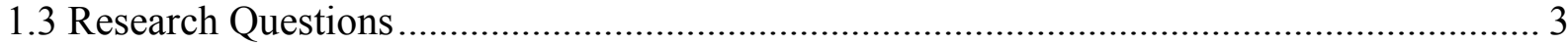

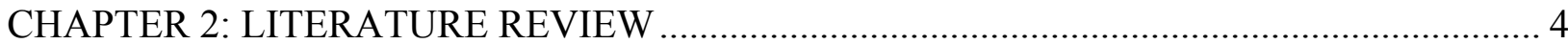

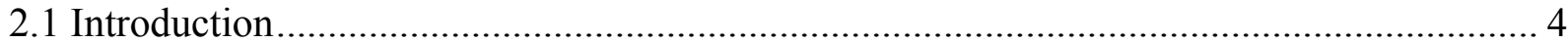

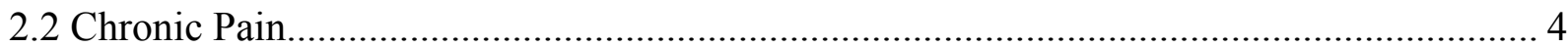

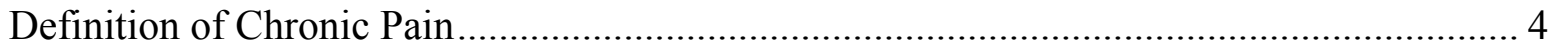

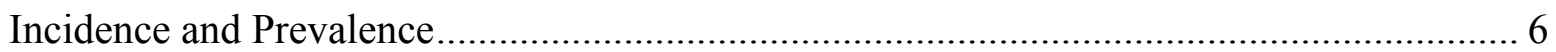

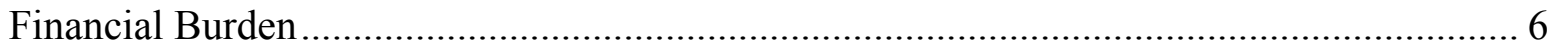

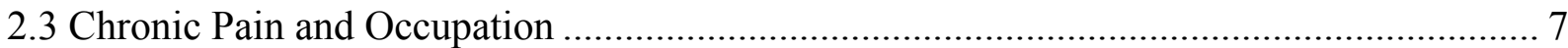

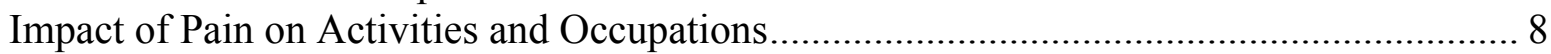

Impact of Pain on Social Relationships ………………................................................... 8

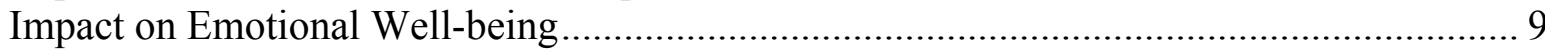

Positive Impact of Occupation on Chronic Pain................................................................ 9

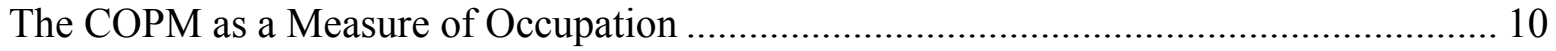

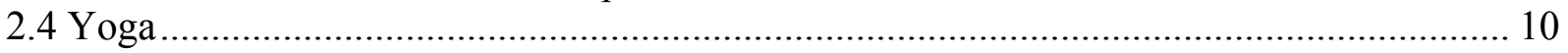

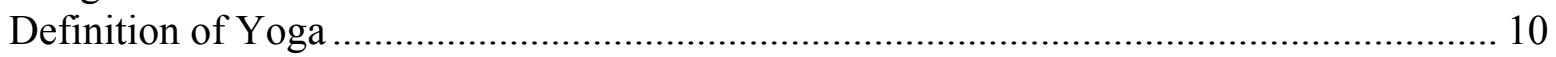

Yoga as an Intervention for Chronic Pain......................................................................... 11

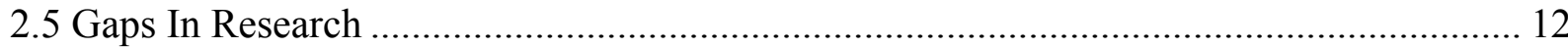

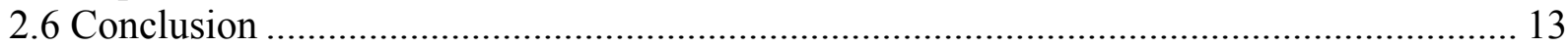

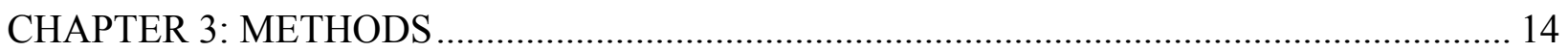

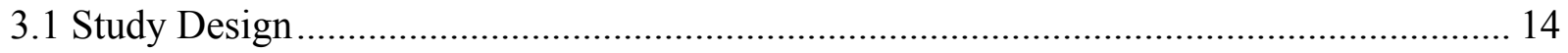

3.2 Primary Author's Position .................................................................................. 14

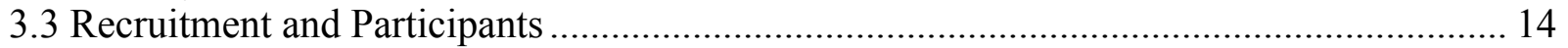

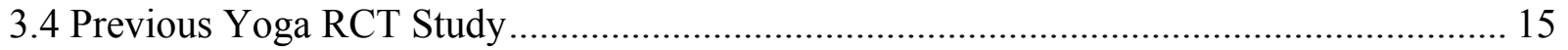

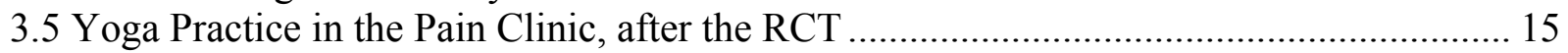

3.6 Data Collection Procedures.............................................................................................. 16

Canadian Occupational Performance Measure (COPM) ………........................................ 16

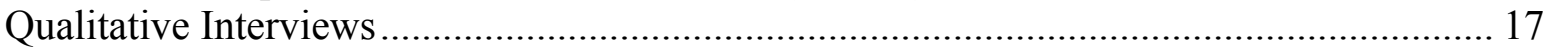

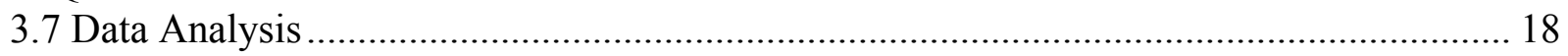

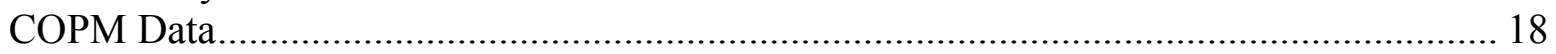

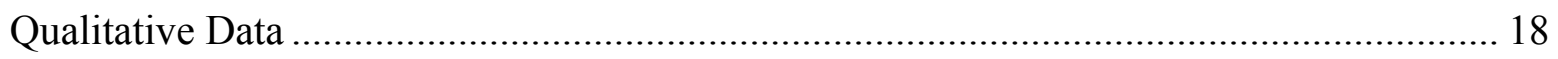

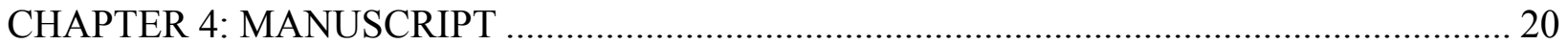

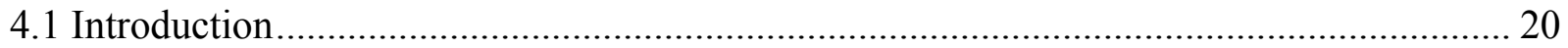

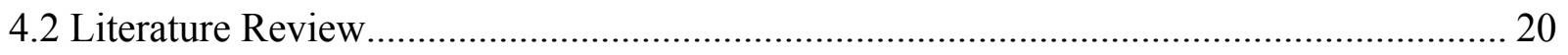




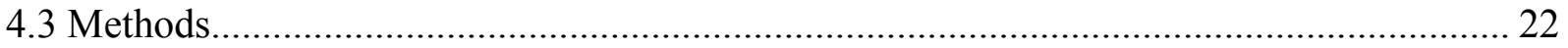

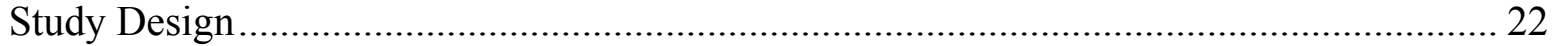

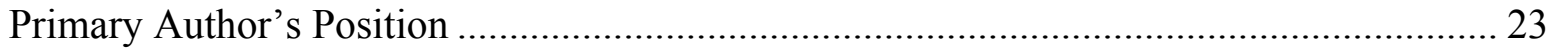

Recruitment and Participants ................................................................................... 23

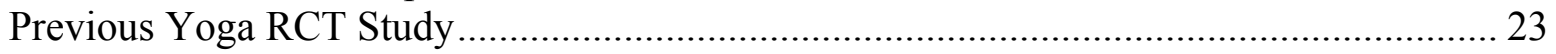

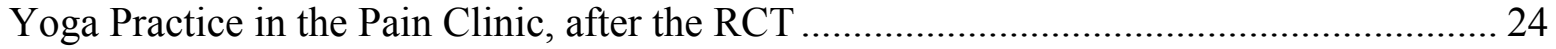

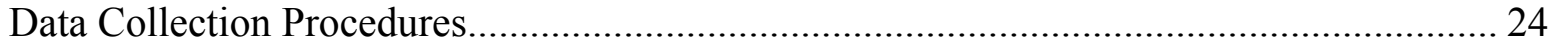

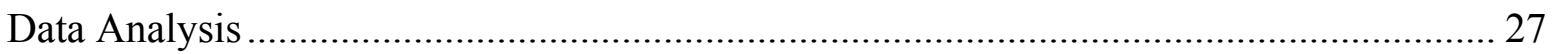

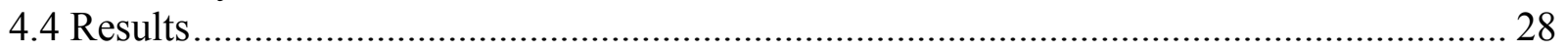

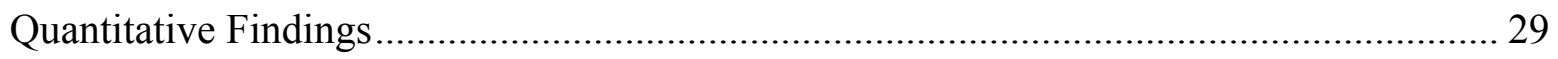

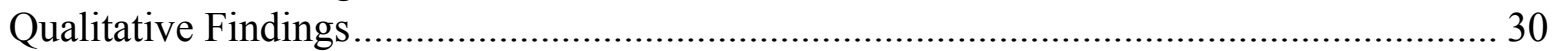

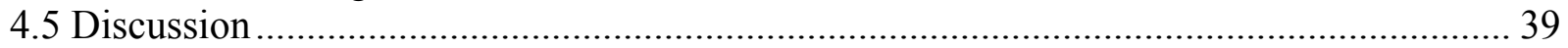

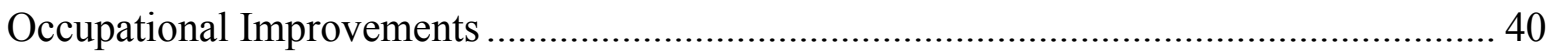

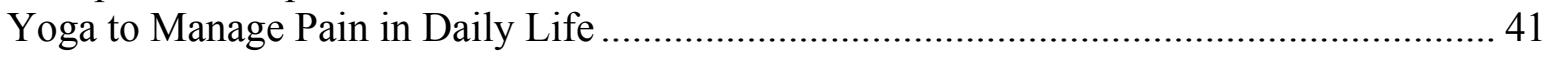

Progression of Health Changes ................................................................................... 42

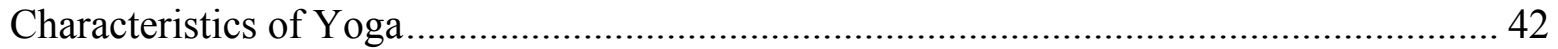

Study Limitations and Future Directions................................................................ 43

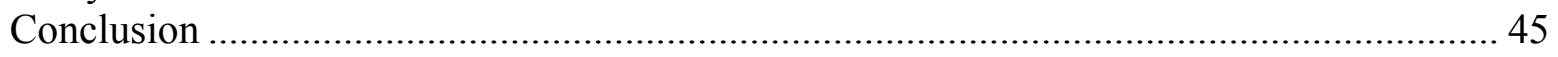

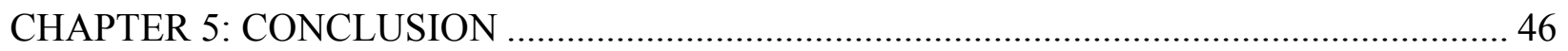

5.1 Implications to Occupational Therapy Practice .......................................................... 46

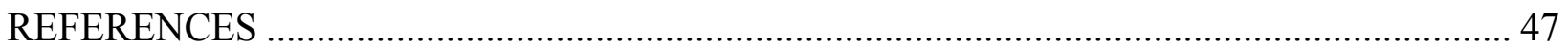

APPENDIX A: INTERVIEW SCRIPT AND QUESTIONS ….......................................... 55 


\section{CHAPTER 1: INTRODUCTION}

\subsection{Purpose}

The purpose of this study was to investigate the perceived impact and experience of longterm involvement in a community-based group yoga class for people with chronic pain. Participants include individuals who attended an 8-week yoga intervention and had the opportunity to continue attending yoga twice a week for approximately 2 years at a community pain clinic. We will gather 1) quantitative and qualitative data on the participants' perceived impact of yoga on occupational performance and satisfaction, and 2) additional qualitative data on the participants' perceived impact of yoga on pain symptoms and perceived experience practicing yoga for chronic pain.

\subsection{Background and Statement of Problem}

Chronic pain is a complex condition that typically originates from acute pain associated with an injury, disease, or disorder (National Institute of Health, 2016). When the acute pain persists for more than 3 months after the underlying cause has been resolved, it becomes a disease itself, known as chronic pain. Chronic pain is a global healthcare epidemic impacting at least 10 percent of the world's population, with an additional 1 in 10 adults newly diagnosed every year (Jackson \& Stabile, 2014). Current treatment for chronic pain is fragmented, costly, and based on a biomedical model. Patients typically experience unnecessary diagnostic tests and potentially harmful treatments, like prescription pain medication and subsequent addiction problems (National Institute of Health, 2016). Because chronic pain is a complex biopsychosocial condition that impacts physical, cognitive, emotional, and social factors, 
treatments that address the whole person are paramount to decreasing prevalence of the disease and increasing optimal health for these individuals (National Institute of Health, 2016).

In addition to the previously identified impacts of chronic pain, current research indicates that chronic pain leads to impairments in occupational performance (Fisher et al., 2007; Persson et al., 2013; Persson, Rivano-Fischer, \& Eklund, 2004). Occupational performance is a person's ability to engage in and accomplish their daily occupations (American Occupational Therapy Association, 2014). Occupations are everyday activities that are meaningful and purposeful to the individual. The literature has shown that people experiencing chronic pain limit their engagement in meaningful and favored activities (Fisher et al., 2007). This decrease in occupational engagement leads to social isolation and emotional distress. Additionally, chronic pain impacts a wide variety of occupations including self-care, work, and leisure (Persson et al., 2013). The inability to perform these occupations can lead to increased dependency on others, loss of life roles, and temporary or permanent disability (Engel, 2001; Rochman, 2014). Given the literature on the prevalence, cost, and impact of chronic pain, it is essential for researchers to consider less costly and more comprehensive holistic treatments that address the individual's unique and complex needs, including supporting and promoting engagement in meaningful occupations.

Yoga is a holistic mind-body intervention that addresses the physical, cognitive, emotional, and social needs of the individual (Mailoo, 2005). Recently, the American Occupational Therapy Association (AOTA) (2016) has acknowledged yoga as a complementary integrative therapy (CIT) that can prepare and enhance participation and engagement in occupations. Researchers have shown that yoga positively impacts the symptoms of chronic pain, including reducing pain and pain-related disability (Bussing et al., 2012; Cramer et al., 2013a; 
Wren et al., 2011), and increasing engagement in daily occupations (Schmid et al., 2018, April;

Willis Boslego et al., 2017a). Specifically, a pilot RCT of an 8-week yoga intervention for individuals with chronic pain found significant improvements in occupational performance and satisfaction, and engagement in daily activities (Schmid et al., 2018, April).

Through previous research, we have begun to better understand the experience of chronic pain, the impact it has on occupational performance, and the positive effects of yoga on the symptoms of chronic pain. However, there is a lack of research investigating the long-term impact of yoga on chronic pain and understanding the experience of those practicing yoga for chronic pain. The purpose of this thesis was to investigate the long-term impact of a communitybased group yoga class for people with chronic pain. Specifically, examining the participants' perceived impact of continued involvement in yoga on their occupations and related chronic pain symptoms, as well as, the participants' perceived experience of engaging in group yoga for chronic pain.

\subsection{Research Questions}

1. What is the perceived impact of yoga on occupational performance and satisfaction for people with chronic pain?

2. What is the perceived impact of yoga on pain-related symptoms (i.e., physical, emotional, and social)?

3. What is the perceived experience of engaging in group yoga for chronic pain? 


\section{CHAPTER 2: LITERATURE REVIEW}

\subsection{Introduction}

This chapter will focus on a review of the literature related to the impact of chronic pain on occupational performance and the effect of yoga interventions on pain, pain-related disability, and occupational performance and satisfaction. To begin, I will define chronic pain and describe its global impact on healthcare. Then, I will summarize the impact of chronic pain on the individual, particularly a person's occupational performance. Following that, I will define yoga and summarize the current research addressing how yoga impacts the chronic pain experience. Lastly, I will identify gaps in research and describe the need for assessing the long-term impact of a community yoga program for people experiencing chronic pain.

\subsection{Chronic Pain}

\section{Definition of Chronic Pain}

Pain is a sensory and emotional experience that plays an important protective role in human health, by alerting a person of actual or potential physical injury (National Institute of Health, 2016). This experience of acute pain can usually be self-managed until the underlying medical cause is treated and resolved. However, when acute pain does not resolve, it may be associated with a serious injury, disease, or condition that requires timely medical care. Additionally, if pain persists, it may signal that pain-initiated changes to the central nervous system have occurred, such as, anatomical alterations to the reward and motivation circuits of the brain (Navratilova et al., 2016). When this happens, the pain is no longer a symptom of another disorder, disease, or injury, but a disease itself known as chronic pain. In most cases, pain that persists for 6 months or more is classified as chronic; however, physicians may diagnose chronic 
pain after one month of persistence so that the patient may receive care as soon as possible (Hoffman, n.d.).

In the literature, chronic pain is described as a complex biopsychosocial condition, highlighting its impact on the mind and body, as well as, a person's social relationships and daily function (National Institute of Health, 2016). The Biopsychosocial Model conceptualizes that the causes and outcomes of chronic pain are an interaction of 1) physical and physiological factors, 2) psychological states and traits, and 3) socio-environmental issues, that together lead to painrelated disability (Engel, 1977; Moseley \& Butler, 2015; see Figure 1). Although these impacts seem to be universal across the pain population, it is also important to note that the pain experience and the perception of pain is subjective and individual, and may differ among people with the same diagnosis (McCaffrey, Frock, \& Garguilo, 2003). It has even been noted that the degree of pain experienced is not reliably associated with the amount of tissue damage acquired (McCaffrey, 2000). Therefore, when researching, assessing, and treating chronic pain, it is important to address the multifaceted and unique needs of the whole person.

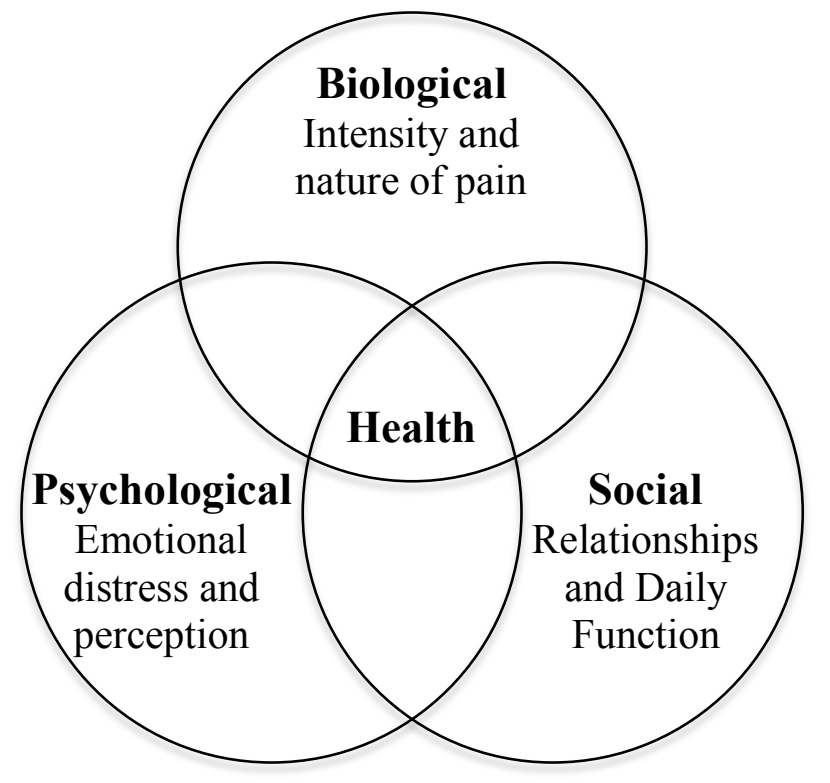

Figure 1. An illustration of Engel's Biopsychosocial Model in relation to chronic pain. 


\section{Incidence and Prevalence}

Chronic pain has been described as a "global burden," a "public health priority," and a “healthcare epidemic” (Global Industry Analysts, 2011; Jackson \& Stabile, 2014; National Institute of Health, 2016). It is estimated that more than 1.5 billion people worldwide are suffering from chronic pain of varying degrees. Each year, 1 in 10 adults are newly diagnosed with chronic pain. The National Institute of Health (NIH) (2016) estimates that over 100 million

people in the United States are affected by chronic pain to some extent. In Great Britain, one half to one third of the population - approximately 28 million people - are currently experiencing chronic pain (Fayaz et al., 2016). Additionally, the prevalence on chronic pain increases with age and females are more likely than males to experience it (Fayaz et al., 2016). In a recent report, the NIH (2016) called for more population research to better understand the scope of the problem and to define healthcare priorities to guide action.

\section{Financial Burden}

In conjunction with rising prevalence, chronic pain has become a costly global issue. A systematic review assessing the cost of chronic low back pain in 8 different countries concluded that direct spending on medical treatment and indirect costs from loss of work productivity were substantial financial burdens on society (Dagenais, Caro, \& Haldeman, 2008). In the United States, the total direct and indirect costs associated with chronic pain are between $\$ 560$ and $\$ 635$ billion (National Institute of Health, 2016). Chronic pain costs in the United Kingdom were 10.7 billion in 1998 (Phillips, 2009). Unfortunately, more current cost analyses of chronic pain in the United Kingdom have not been reported. More current research is needed to better understand the magnitude of the global economic burden of chronic pain. 
Additionally, people with chronic pain are receiving fragmented care, including unnecessary diagnostic tests and ineffective potentially harmful treatments, that are linked to high healthcare costs (National Institute of Health, 2016). Specifically, the prevalence and misuse of prescription pain medications, known as the opioid epidemic, is extremely costly and detrimental to patients' health. The number of opioid prescriptions dispensed has risen from 76 million in 1999 to 219 million in 2011 (National Institute of Health, 2016). This increase in prescribing of opioids has led to a significant rise in addiction, abuse, overdose, and diagnosis of depression. In response to this increase, the United States declared the opioid crisis a public health emergency (Davis, 2017). Given this data, it is essential for researchers to consider less costly, holistic, non-pharmaceutical treatments, like yoga, that address the physical, emotional, social, and occupational needs of individuals with chronic pain.

\subsection{Chronic Pain and Occupation}

Chronic pain is a life-changing experience that impacts nearly every occupation in a person's life (Fisher et al., 2007). Occupations can be defined as everyday activities that are meaningful and/or purposeful to the individual, including activities of daily living (ADLs), instrumental ADLs (IADLs), work, leisure, recreation, and social participation (American Occupational Therapy Association, 2014). Inability to perform these occupations can lead to increased dependency on others, loss of worker and family roles, difficulty participating in everyday activities, and temporary or permanent disability (Engel, 2001; Rochman, 2014). Researchers have conducted studies to better understand the impact of chronic pain on individuals' lives. This portion of the literature review will summarize how chronic pain impacts activities and occupations, as well as, how chronic pain's impact on social relationships and emotional well-being relate back to occupational difficulties. 


\section{Impact of Pain on Activities and Occupations}

To better understand the pain experience, researchers have conducted studies to assess how daily occupations and activities are impacted (Fisher et al., 2007; Persson et al., 2013; Persson et al., 2004). In a qualitative study, individuals reported limiting their activities due to pain, changing or avoiding plans when pain was present or expected, participating less in social activities, and decreasing engagement in favored activities (Fisher et al., 2007). Other researchers described the diversity of everyday occupational problems among patients with musculoskeletal pain enrolled in a pain management program (Persson et al., 2013). They found that the occupational problems were evenly distributed between 3 categories: self-care (37\%), productivity (32\%), and leisure (31\%). The most frequently reported everyday occupational problems were working; sitting; cleaning the house; cooking; and sleeping. Collectively, these researchers suggest that occupational performance problems due to pain are widespread across many different occupations including ADLs, IADLs, productivity, leisure, and socialization (Fisher et al., 2007; Persson et al., 2013; Persson et al., 2004).

\section{Impact of Pain on Social Relationships}

The impact of chronic pain on social relationships was a theme expanded on by Fisher et al. (2007). Individuals with chronic pain noted that pain experiences changed the nature of relationships with others. Participants would hide their pain from others out of fear that they would not understand. Friends tended to not understand what participants were going through, and would therefore drift out of their lives. Participants expressed shame for becoming more dependent on their family members and difficulty asking for help. Collectively, all of these factors affected the participants' enjoyment and involvement in the occupation of socialization. 


\section{Impact on Emotional Well-being}

In addition to pain impacting social relationships, there seems to be a complex bidirectional relationship between chronic pain and emotional distress. Fisher et al. (2007) found that chronic pain elicits emotional distress. Participants expressed feelings of depression related to being unable to complete usual day-to-day activities, frustration with healthcare providers' inability to understand chronic pain, and anxiety and fear about when pain might interfere with daily activities. Alternatively, an increase in emotional distress may lead to feeling more pain (Fishbain et al., 1997; McCaffrey, 2000). When depression and anxiety accompany pain, the coexisting psychological distress is a predictor of more recalcitrant chronic pain. Given this transactional relationship, it is important to jointly address the physical and psychological factors when treating those with chronic pain.

\section{Positive Impact of Occupation on Chronic Pain}

Researchers have also indicated that participation in occupation has a positive impact on decreasing the pain experience. Participants in a variety of qualitative studies indicated that participation in enjoyable activities could divert attention away from pain and increase the flow experience (Aegler \& Satink, 2009; Fisher et al., 2007; Stevens-Ratchford \& Lookingbill, 2004). Participants also discussed implementing "adaptive responses," including: changing routines (e.g., allocating more time for a task and using assistive technology); energy conservation techniques (e.g., taking breaks and asking for help from others); and cognitive adaptions (e.g., thinking positively). Melzack (1982) postulates that experiencing distractions, such as music, humor, or spending time with a loved one can also reduce the perception of pain. Given these data, a leisure occupation, such as group yoga, has the potential to improve emotional well- 
being, increase socialization with people going through a similar experience, and increase a person's physical ability to participate in meaningful occupations.

\section{The COPM as a Measure of Occupation}

The Canadian Occupational Performance Measure (COPM) is an assessment that has been used to measure changes in participants' perception of their occupational performance and satisfaction with occupational performance (Law et al., 1998). Occupational performance can be defined as the accomplishment of a selected occupation resulting from the dynamic transaction between the client, the context, and the occupation (American Occupational Therapy Association, 2014). Occupational satisfaction can be defined as one's perception of progress towards the goal of performing an occupation. Walsh et al. (2003a) noted that the COPM is a useful tool for identifying the problems of individuals with chronic low-back pain, as the COPM provides a patient-focused outcome measure and allows the patient to select aspects of performance that are of greatest concern to the individual. Additionally, researchers using the COPM as an outcome measure for pain rehabilitation interventions found statistically significant positive changes to perception of occupational performance and occupational satisfaction postintervention for people with chronic pain (Persson et al., 2013; Persson et al., 2004; Walsh et al., 2003b). The research supports that the COPM is a sensitive and appropriate measure to detect change in participants' perception of occupational performance and satisfaction.

\subsection{Yoga}

\section{Definition of Yoga}

Yoga is a holistic mind-body intervention that addresses the physical, cognitive, emotional, and social needs of the individual. It typically includes asanas (physical postures), pranayama (diaphragmatic breathing and breathing with movement), mantras (positive 
affirmations that are repeated during the yoga session), and dhyana (meditation with relaxation) (Nayak \& Shankar, 2004). It is acknowledged as a form of complementary integrative medicine (CIM) and complementary integrative therapy (CIT) that can "prepare and enhance participation and engagement in occupation by persons, groups, and populations" (American Occupational Therapy Association, 2016).

\section{Yoga as an Intervention for Chronic Pain}

A number of systematic reviews and meta-analyses assessed the effectiveness of shortterm yoga interventions on pain and pain-related disability. Posadzki et al. (2011) performed a systematic review of randomized control trials (RCTs) to assess the effectiveness of yoga as a treatment option for multiple types of pain. The nine studies included in the review suggested that yoga leads to significantly greater reduction in pain than various control interventions. Wren et al. (2011) reviewed controlled studies to shed light on the potential role that yoga can play in pain management for a range of conditions (i.e., carpal tunnel syndrome, hand osteoarthritis, persistent low back pain, fibromyalgia, end stage renal disease, and cancer). Wren et al. (2011) reported improvements in pain, strength, functional disability, sleep disturbance, fatigue, and mood. Bussing et al. (2012) performed a meta-analysis on the effectiveness of yoga interventions on pain and pain-associated disability. Sixteen controlled trials that encompassed a variety of chronic pain diagnoses (i.e., back pain, rheumatoid arthritis, headache/migraine, and other indications) suggested that yoga is supportive in reducing pain intensity, pain frequency, and pain-associated disability. Lastly, Cramer et al. (2013a) performed a systematic review and metaanalysis to assess the effectiveness of yoga for low back pain. Findings suggested strong evidence for short-term effects of pain, back-specific disability, and global improvement, and moderate evidence of long-term effect on back-specific disability. Based on these reviews, yoga 
is an established intervention that is shown to improve pain, pain-related disability, and other associated symptoms in those experiencing chronic pain.

Despite ample research on yoga as an effective intervention for chronic pain, there is a lack of research that examines the impact of yoga on improving occupational performance and satisfaction outcomes of people with chronic pain. Willis-Boslego et al. (2017b) assessed an 8week yoga intervention for people with diabetic peripheral neuropathy and found that both pain and occupational performance improved. Schmid et al. (2018, April) conducted an 8-week pilot RCT of a yoga intervention for individuals with chronic pain and found significant improvements in occupational performance, satisfaction of performance, and engagement in daily occupation for those within the yoga intervention group. These preliminary findings suggest that short-term yoga interventions have the potential to improve occupational performance and satisfaction in those with chronic pain. However, larger scale studies with follow-up data are needed to further support these findings and ensure that changes are sustained over time with continued engagement in yoga.

\subsection{Gaps In Research}

Despite the increase in literature on the effectiveness of yoga for chronic pain, there are still gaps that need to be filled. When follow-up data has been gathered for yoga intervention studies addressing pain and pain-related disability, they are typically 3-month and 6-month postyoga follow-ups. Long-term follow-ups are needed to assess if changes are sustained after yoga interventions have concluded (Wren et al., 2011). Furthermore, no literature exists exploring the impact of on-going participation in yoga for chronic pain - exploring this domain would help us further understand the benefits of long-term yoga involvement. Additionally, participants in the majority of studies are Caucasian, middle-aged, female, and of higher socioeconomic status 
(SES). Future studies need to determine whether yoga is efficacious for people of diverse backgrounds with respect to ethnicity, age, gender, and SES. Research that examines the use of yoga to improve occupational performance and satisfaction outcomes of people with chronic pain are lacking and would be beneficial to inform the impact of yoga on occupation. Lastly, although controlled trials are beneficial for indicating effectiveness, more studies addressing the impact of yoga happening in the uncontrolled community environment would increase generalizability.

\subsection{Conclusion}

This study will help fill the gaps in the research by collecting 2-year follow-up COPM and qualitative exploratory data on participants who initially took part in a randomized control trial (RCT) of an 8-week yoga intervention vs. usual care for chronic pain at a community-based Pain Clinic (Schmid et al., 2018, April). Results from the RCT showed initial improvements in

physical, emotional, and occupational factors of chronic pain. Long-term follow-up data from the current study will allow us to assess how impactful yoga is on maintaining improvements to physical, emotional, and occupational factors. Additionally, assessing a community yoga program allows us to evaluate how yoga benefits individuals in a natural, realistic, and uncontrolled environment. Lastly, it will be novel to gather qualitatively data investigating participants' perceived impact of yoga on occupations and pain-related symptoms, as well as, participants' perceived experience of engaging in group yoga for chronic pain. 


\section{CHAPTER 3: METHODS}

\subsection{Study Design}

This study used a mixed methods design to explore the perceived impact of long-term involvement in group yoga for individuals with chronic pain. Participants from a previous RCT, who had been attending yoga for approximately 2 years, completed an individual qualitative interview and a follow-up Canadian Occupational Performance Measure (COPM) during the same visit. Qualitative findings were used to confirm and strengthen quantitative COPM results.

\subsection{Primary Author's Position}

The primary author of this study (CR) has practiced yoga for 10 years, and in the last year, has used yoga therapy as a modality to cope with recurrent pain. CR believes that yoga has contributed to positive changes in her physical, mental, and emotional health. Currently, CR is exploring her interest in yoga and meditation as a spiritual practice. In an attempt to limit her personal bias towards the benefits of yoga, CR used the following methodological procedures: 1) using multiple interview coders and peer reviewers, 2) recording a detailed audit trail of notes tracking the data collection and analysis process, and 3) conducting continual research reflection and check-in discussions with the other researchers about positioning.

\subsection{Recruitment and Participants}

Inclusion criteria for the original RCT included: 1) current patients at the Pain Clinic; 2) at least 6 months of chronic pain; 3) >18 years old; 4) no restriction on physical activity; 5) no consistent yoga in the past year; and 6) willing to provide consent to enter the study (Schmid, in review). Thirteen participants from the RCT met the following inclusion criteria and were recruited for the current study: 1) participated in the previous yoga RCT study for chronic pain at 
the Pain Clinic in Fort Collins, CO, 2) randomized into the yoga group, and 3) self-reported continued attendance in yoga classes at the Pain Clinic approximately 1 day a week for 2 years.

\subsection{Previous Yoga RCT Study}

During the previous yoga RCT study, participants were randomized into the yoga intervention group or the usual care control group. Participants in the yoga intervention group received 1-hour yoga sessions twice a week for eight weeks (16 sessions total). The yoga protocol included a standardized and progressive intervention of sitting, standing, and floor postures. Yoga included physical postures, breath work (to connect the movement to the breath), mantras, and meditation/relaxation. Full details of the yoga intervention are published elsewhere (Schmid, in review). After the yoga intervention concluded, the Pain Clinic continued to offer yoga due to client interest and improvements is physical, emotional, and social health.

\subsection{Yoga Practice in the Pain Clinic, after the RCT}

Yoga continues to be offered twice a week to participants from the RCT. Participants choose between two types of yoga: 1) chair-only yoga postures or 2) floor and standing yoga postures. The yoga sessions continue to incorporate physical postures, breath work, mantras, and meditation/relaxation exercises. The yoga sessions are taught by a registered yoga teacher and occupational therapist who also taught the yoga sessions during the RCT. Similar to the RCT, the yoga teacher offers a variety of modifications and props for each participant throughout the yoga sessions. Additionally, as the yoga teacher is an occupational therapist, she asks participants about occupational difficulties in daily life and provides individualized yoga sequences to improve performance of specific activities. 


\subsection{Data Collection Procedures}

The COPM was completed by each participant during the RCT and was completed again for the current study. At the point of data collection for this current study, participants had been attending yoga for approximately 2 years at the Pain Clinic (including the time of the RCT). Two-year COPM data were compared to baseline COPM data from the previous yoga RCT to assess change in self-reported occupational performance and satisfaction. Individual qualitative interviews were conducted to assess the perceived: impact of yoga on occupational performance and satisfaction; impact of yoga on pain-related symptoms (i.e., physical, emotional, and social factors); and the experience of continued yoga involvement for chronic pain. Demographic data collected during the previous study was also reported.

\section{Canadian Occupational Performance Measure (COPM)}

Quantitative measures of occupational performance and satisfaction were assessed using the COPM. The COPM is a standardized, client-centered assessment tool that enables individuals to identify and prioritize issues that restrict or impact their performance in everyday living (Law et al., 1998). It is designed to measure changes in the client's self-perception of their occupational performance and satisfaction with performance in areas of self-care, productivity, and leisure over time (Law et al., 1990). First, the client identifies five occupations that they are unable to perform satisfactorily. Then, the individual rates, on a scale of 1-10, their ability to perform each activity and their satisfaction with performance of each activity ( $1=$ low performance/satisfaction, 10=high performance/satisfaction). After a period of treatment or intervention, the client completes a reassessment by rating their performance and satisfaction of the five activities again. Mean change scores of performance and satisfaction from baseline to reassessment are calculated. Higher scores indicate improved perception of occupational 
performance and satisfaction with performance. Mean change scores of two or more points indicates a clinically significant improvement in performance and/or satisfaction (Law et al., 1998). The COPM has high test-retest reliability and high predictive and concurrent validity (Sewell \& Singh, 2001). Additionally, studies have indicated that the COPM is sensitive to changes in occupational performance and satisfaction for people with pain (Carpenter, Baker, \& Tyldesley, 2001; Carswell et al., 2004; Persson et al., 2014; Walsh et al., 2003b).

The COPM was completed in person at the Pain Clinic with the primary author midway through the qualitative interview. First, participants were reminded of their five previously identified occupational problems from the previous yoga intervention. Then, participants rated, on a scale of 1-10, their ability to perform each activity and their satisfaction with their performance of each activity.

\section{Qualitative Interviews}

Individual interviews took place in-person in a private room at the Pain Clinic, with the exception of one phone interview. The primary researcher (CR) led the interviews that lasted 45 minutes to one hour each. Individual interviews were conducted to investigate the participants' perceived impact of yoga on occupational performance and satisfaction and on pain-related symptoms (i.e., physical, emotional, and social). Additionally, interviews explored participants' perceived experience of practicing yoga for chronic pain. During the first half of the interview, participants were asked about the experience of practicing yoga for chronic pain and how yoga had impacted pain-related symptoms (see Appendix A). Open-ended and neutrally worded questions, along with probes, supported a systematic and comprehensive line of inquiry in an attempt to support the researcher's neutral stance (Merriam, 2009). Sample questions included: "What is your favorite part of yoga? What led you to continue practicing yoga? Since doing 
yoga, what changes have you noticed? How is yoga different from other things you've tried to manage pain?" Probes guided the participants to think specifically about physical, mental, emotional, and social factors impacted by yoga. Midway through the interview, the COPM was administered and participants observed how their scores of performance and satisfaction had changed or stayed the same. Then, the researcher asked probing question including: "What do you think led to this change in performance? What do you think led to this change in satisfaction? When looking at these changes, how does that make you feel?" The interviews were audio recorded and transcribed verbatim.

\subsection{Data Analysis}

\section{COPM Data}

Quantitative data were analyzed using SPSS statistics 24 software (SPSS Inc, Chicago, IL). Descriptive statistics, including the mean, standard deviations, frequencies and proportions were used to describe the sample. Due to the small sample size, Wilcoxon signed rank nonparametric tests were used to compare baseline COPM scores to COPM scores gathered after approximately 2 years of attending yoga. Percent change for the COPM was calculated (Time 1Time 2/Time 1x100). A change of 2 points or more on mean COPM scores from baseline to 2 years were also assessed to determine clinical significance.

\section{Qualitative Data}

All interview transcripts were entered into Nvivo 11 software (QSR International, Melbourne, Australia). Analyses were guided by an inductive process allowing codes and themes to emerge from the data (Creswell, 2013). To begin, four researchers individually read two transcripts to become acquainted with the data, obtain overall impressions, and generate tentative codes. Next, the four researchers met to discuss overall impressions and initiate development of 
codes. Once the primary author developed an initial coding list, the four researchers coded two interviews individually and met to reach consensus. The remaining interviews were coded by CR and one other researcher. To begin identifying larger themes, sub-themes were generated and organized across interviews. The four researchers met to collapse sub-themes into larger themes and ensure final themes were grounded in the data.

The following validation strategies were used to increase rigor of analysis: clarification of researcher bias; simultaneous data collection and data analysis; peer review or debriefing; and rich, thick description (Creswell, 2013). To clarify researcher biases, CR provided a positioning statement identifying biases towards the topic and the data that may have impacted the results. Additionally, data analysis occurred in conjunction with data collection so that guiding questions could be re-analyzed and adjusted to ensure questions allowed for saturation. Peer review and debriefing were used as the researchers noted and debated their contradicting ideas in order to fully understand participants' experiences and reach consensus. Lastly, rich and thick description was used when recording audit trail notes to ensure CR's reflexivity and trustworthiness. 


\section{CHAPTER 4: MANUSCRIPT}

\subsection{Introduction}

Chronic pain is a global healthcare epidemic impacting at least 10 percent of the world's population, with an additional 1 in 10 adults newly diagnosed every year (Jackson \& Stabile, 2014). Current standard of care for chronic pain is based on a biomedical model of prescription pain medication to temporarily mitigate physical symptoms (National Institute of Health, 2016). Research is beginning to support more holistic biopsychosocial treatment approaches that target the person's physical, emotional, and social symptoms related to chronic pain (Kamper et al., 2015). Yoga is one such intervention shown to positively impact biopsychosocial symptoms of chronic pain, as well as, increase engagement in occupations (Bussing et al., 2012; Cramer et al., 2013a; Wren et al., 2011). Currently, research is limited to controlled short-term yoga intervention studies, and little to no research has been conducted on the long-term impact of yoga for chronic pain occurring in the community. The aim of this study was to investigate the longterm impact of a community-based group yoga class for people with chronic pain. Specifically, examining the participants' perceived impact of continued involvement in yoga on their occupations and related chronic pain symptoms, as well as, the participants' perceived experience of engaging in group yoga for chronic pain.

\subsection{Literature Review}

Recent research indicates that chronic pain negatively impacts occupational performance and occupational engagement in purposeful and meaningful activities (Fisher et al., 2007; Persson et al., 2013; Persson et al., 2004). A wide variety of occupations become challenging for people with chronic pain, including self-care activities, household management, work, and 
leisure (Persson et al., 2013). When occupations become challenging, people with chronic pain tend to decrease occupational engagement, leading to social isolation and emotional distress (Fisher et al., 2007). Furthermore, the inability to perform these occupations can lead to increased dependency on others, loss of life roles, and temporary or permanent disability (Engel, 2001; Rochman, 2014).

Despite knowledge that chronic pain impacts the whole person, current standard practice is still based on a biomedical model of costly prescription pain medication that may temporarily reduce physical symptoms (National Institute of Health, 2016). Research is beginning to support more holistic biopsychosocial treatments for chronic pain that target the physical, psychological, and social aspects of pain (Kamper et al., 2015). Researchers have found that biopsychosocial interventions are more effective than usual care in improving pain, functioning, and disability in people with chronic pain (Guzman et al., 2006; Kamper et al., 2015; Marin et al., 2017). Given the literature on effectiveness of biopsychosocial intervention, it is essential for researchers to consider less costly and more comprehensive holistic treatments.

Yoga is a holistic mind-body intervention that addresses the physical, cognitive, emotional, and social needs of the individual (Mailoo, 2005). Recently, the American Occupational Therapy Association (AOTA) (2016) acknowledged yoga as a complementary integrative therapy (CIT) that can prepare and enhance participation and engagement in occupations. Researchers have shown that short-term yoga interventions positively impact the symptoms of chronic pain, including reducing pain and pain-related disability (Bussing et al., 2012; Cramer et al., 2013a; Wren et al., 2011), decreasing anxiety and depression (Tekur et al., 2012), and increasing engagement in daily occupations (Schmid, in review; Willis Boslego et al., 2017b). However, little to no research has been conducted on the long-term impact of yoga for 
chronic pain occurring in the community. Further research gathering long-term follow-up data will help determine if yoga is an effective method for maintaining positive changes to chronic pain.

The current study aimed to fill this gap by gathering follow-up data from participants who initially took part in a randomized control trial (RCT) of an 8-week yoga intervention vs. usual care for individuals with chronic pain at a community-based Pain Clinic (Schmid, in review). Results from the RCT study found significant improvements for participants randomized to the yoga intervention including improved: strength; balance; body responsiveness; pain-related disability; occupational performance; and self-efficacy (Schmid et al., 2018, April). The medical providers and the administration at the Pain Clinic were very pleased with these results, and therefore, began to offer group yoga, free of charge, to the patients of the Pain Clinic. The yoga sessions continued to be offered twice a week by the same yoga teacher/occupational therapist who taught yoga for the RCT. The current study followed up with participants 2 years after the original RCT who were still attending yoga at the Pain Clinic. In doing so, this study aimed to understand the long-term benefits of yoga on chronic pain. Specifically, participants' perceived impact of yoga on occupations and other pain-related symptoms, as well as, participants' perceived experience of long-term involvement in yoga for chronic pain.

\subsection{Methods}

\section{Study Design}

This study used a mixed methods design to explore the perceived impact of long-term involvement in group yoga for individuals with chronic pain. Participants from a previous RCT, who had been attending yoga for approximately 2 years, completed an individual qualitative 
interview and a follow-up Canadian Occupational Performance Measure (COPM) during the same visit. Qualitative findings were used to confirm and strengthen quantitative COPM results.

\section{Primary Author's Position}

The primary author of this study (CR) has practiced yoga for 10 years, and in the last

year, has used yoga therapy as a modality to cope with recurrent pain. CR believes that yoga has contributed to positive changes in her physical, mental, and emotional health. Currently, CR is exploring her interest in yoga and meditation as a spiritual practice. In an attempt to limit her personal bias towards the benefits of yoga, CR used the following methodological procedures: 1) using multiple interview coders and peer reviewers, 2) recording a detailed audit trail of notes tracking the data collection and analysis process, and 3) conducting continual research reflection and check-in discussions with the other researchers about positioning.

\section{Recruitment and Participants}

Inclusion criteria for the original RCT included: 1) current patients at the Pain Clinic; 2) at least 6 months of chronic pain; 3)>18 years old; 4) no restriction on physical activity; 5) no consistent yoga in the past year; and 6) willing to provide consent to enter the study (Schmid, in review). Thirteen participants from the RCT met the following inclusion criteria and were recruited for the current study: 1) participated in the previous yoga RCT study for chronic pain at the Pain Clinic in Fort Collins, CO, 2) randomized into the yoga group, and 3) self-reported continued attendance in yoga classes at the Pain Clinic approximately 1 day a week for 2 years.

\section{Previous Yoga RCT Study}

During the previous yoga RCT study, participants were randomized into the yoga intervention group or the usual care control group. Participants in the yoga intervention group received 1-hour yoga sessions twice a week for eight weeks (16 sessions total). The yoga 
protocol included a standardized and progressive intervention of sitting, standing, and floor postures. Yoga included physical postures, breath work (to connect the movement to the breath), mantras, and meditation/relaxation. Full details of the yoga intervention are published elsewhere (Schmid, in review). After the yoga intervention concluded, the Pain Clinic continued to offer yoga due to client interest and improvements is physical, emotional, and social health.

\section{Yoga Practice in the Pain Clinic, after the RCT}

Yoga continues to be offered twice a week to participants from the RCT. Participants choose between two types of yoga: 1) chair-only yoga postures or 2) floor and standing yoga postures. The yoga sessions continue to incorporate physical postures, breath work, mantras, and meditation/relaxation exercises. The yoga sessions are taught by a registered yoga teacher and occupational therapist who also taught the yoga sessions during the RCT. Similar to the RCT, the yoga teacher offers a variety of modifications and props for each participant throughout the yoga sessions. Additionally, as the yoga teacher is an occupational therapist, she asks participants about occupational difficulties in daily life and provides individualized yoga sequences to improve performance of specific activities.

\section{Data Collection Procedures}

The COPM was completed by each participant during the RCT and was completed again for the current study. At the point of data collection for this current study, participants had been attending yoga for approximately 2 years at the Pain Clinic (including the time of the RCT). Two-year COPM data were compared to baseline COPM data from the previous yoga RCT to assess change in self-reported occupational performance and satisfaction. Individual qualitative interviews were conducted to assess the perceived: impact of yoga on occupational performance and satisfaction; impact of yoga on pain-related symptoms (i.e., physical, emotional, and social 
factors); and the experience of continued yoga involvement for chronic pain. Demographic data collected during the previous study was also reported.

\section{Canadian Occupational Performance Measure (COPM)}

Quantitative measures of occupational performance and satisfaction were assessed using the COPM. The COPM is a standardized, client-centered assessment tool that enables individuals to identify and prioritize issues that restrict or impact their performance in everyday living (Law et al., 1998). It is designed to measure changes in the client's self-perception of their occupational performance and satisfaction with performance in areas of self-care, productivity, and leisure over time (Law et al., 1990). First, the client identifies five occupations that they are unable to perform satisfactorily. Then, the individual rates, on a scale of 1-10, their ability to perform each activity and their satisfaction with performance of each activity (1=low performance/satisfaction, 10=high performance/satisfaction). After a period of treatment or intervention, the client completes a reassessment by rating their performance and satisfaction of the five activities again. Mean change scores of performance and satisfaction from baseline to reassessment are calculated. Higher scores indicate improved perception of occupational performance and satisfaction with performance. Mean change scores of two or more points indicates a clinically significant improvement in performance and/or satisfaction (Law et al., 1998). The COPM has high test-retest reliability and high predictive and concurrent validity (Sewell \& Singh, 2001). Additionally, studies have indicated that the COPM is sensitive to changes in occupational performance and satisfaction for people with pain (Carpenter et al., 2001; Carswell et al., 2004; Persson et al., 2014; Walsh et al., 2003b).

The COPM was completed in person at the Pain Clinic with the primary author midway through the qualitative interview. First, participants were reminded of their five previously 
identified occupational problems from the previous yoga intervention. Then, participants rated, on a scale of 1-10, their ability to perform each activity and their satisfaction with their performance of each activity.

\section{Qualitative Interviews}

Individual interviews took place in-person in a private room at the Pain Clinic, with the exception of one phone interview. The primary researcher (CR) led the interviews that lasted 45 minutes to one hour each. Individual interviews were conducted to investigate the participants' perceived impact of yoga on occupational performance and satisfaction and on pain-related symptoms (i.e., physical, emotional, and social). Additionally, interviews explored participants' perceived experience of practicing yoga for chronic pain. During the first half of the interview, participants were asked about the experience of practicing yoga for chronic pain and how yoga had impacted pain-related symptoms (see Appendix A). Open-ended and neutrally worded questions, along with probes, supported a systematic and comprehensive line of inquiry in an attempt to support the researcher's neutral stance (Merriam, 2009). Sample questions included: "What is your favorite part of yoga? What led you to continue practicing yoga? Since doing yoga, what changes have you noticed? How is yoga different from other things you've tried to manage pain?" Probes guided the participants to think specifically about physical, mental, emotional, and social factors impacted by yoga. Midway through the interview, the COPM was administered and participants observed how their scores of performance and satisfaction had changed or stayed the same. Then, the researcher asked probing question including: "What do you think led to this change in performance? What do you think led to this change in satisfaction? When looking at these changes, how does that make you feel?" The interviews were audio recorded and transcribed verbatim. 


\section{Data Analysis}

\section{COPM Data}

Quantitative data were analyzed using SPSS statistics 24 software (SPSS Inc, Chicago, IL). Descriptive statistics, including the mean, standard deviations, frequencies and proportions were used to describe the sample. Due to the small sample size, Wilcoxon signed rank nonparametric tests were used to compare baseline COPM scores to COPM scores gathered after approximately 2 years of attending yoga. Percent change for the COPM was calculated (Time 1Time 2/Time $1 \times 100)$. A change of 2 points or more on mean COPM scores from baseline to 2 years were also assessed to determine clinical significance.

\section{Qualitative Data}

All interview transcripts were entered into Nvivo 11 software (QSR International, Melbourne, Australia). Analyses were guided by an inductive process allowing codes and themes to emerge from the data (Creswell, 2013). To begin, four researchers individually read two transcripts to become acquainted with the data, obtain overall impressions, and generate tentative codes. Next, the four researchers met to discuss overall impressions and initiate development of codes. Once CR developed an initial coding list, the four researchers coded two interviews individually and met to reach consensus. The remaining interviews were coded by $\mathrm{CR}$ and one other researcher. To begin identifying larger themes, sub-themes were generated and organized across interviews. The four researchers met to collapse sub-themes into larger themes and ensure final themes were grounded in the data.

The following validation strategies were used to increase rigor of analysis: clarification of researcher bias; simultaneous data collection and data analysis; peer review or debriefing; and rich, thick description (Creswell, 2013). To clarify researcher biases, CR provided a positioning 
statement identifying biases towards the topic and the data that may have impacted the results. Additionally, data analysis occurred in conjunction with data collection so that guiding questions could be re-analyzed and adjusted to ensure questions allowed for saturation. Peer review and debriefing were used as the researchers noted and debated their contradicting ideas in order to fully understand participants' experiences and reach consensus. Lastly, rich and thick description was used when recording audit trail notes to ensure CR's reflexivity and trustworthiness.

\subsection{Results}

Thirteen participants still attending yoga at the Pain Clinic were recruited for the study. Of the thirteen participants, eleven took part in the study. One person declined to participate due to time constraints and one person was excluded due to 6 months of inconsistent yoga attendance secondary to illness. At baseline, participants ranged from 37 to 71 years of age, with an average age of 58 years $(\mathrm{SD}=9.34)$. The majority of participants had experienced over 10 years of chronic pain (82\%) and identified trauma as the cause of pain (73\%; see Table 1$)$. 
Table 1. Demographics of participants.

\begin{tabular}{lc}
\hline Characteristics & Total $(n=11)$ \\
\hline Age (years), $M(\mathrm{SD})$ & $58 \pm 9.34$ \\
Sex (female) & $9(82 \%)$ \\
Race (white) & $6(55 \%)$ \\
Education (less than some college) & $6(55 \%)$ \\
Married or part of a couple & $6(55 \%)$ \\
Years of chronic pain (>10 years) & $9(82 \%)$ \\
Cause of pain (trauma) & $8(73 \%)$ \\
\hline
\end{tabular}

\section{Quantitative Findings}

COPM performance and satisfaction scores significantly improved between baseline and follow up after 2 years of yoga (see Table 2). Performance scores improved by $64 \%(4.10 \pm 1.32$ vs. $6.76 \pm 1.50, p<.005)$. Satisfaction scores improved by $154 \%(2.44 \pm 2.28$ vs. $6.20 \pm 2.03$, $p<.008)$. This improvement was clinically significant because both mean scores changed by more than two points.

Table 2. Change in COPM scores between baseline and 2 years of yoga, $n=10$.

\begin{tabular}{lllll}
\hline COPM Scores $(n=10)$ & Baseline & 2 years of yoga & $P$ value & $\begin{array}{l}\text { \% change } \\
\text { T1-T2/T1*100 }\end{array}$ \\
\hline Occupational Performance & $4.10 \pm 1.32$ & $6.76 \pm 1.50$ & .005 & $64 \%$ \\
Occupational Satisfaction & $2.44 \pm 2.28$ & $6.20 \pm 2.03$ & .008 & $154 \%$ \\
\hline
\end{tabular}




\section{Qualitative Findings}

Three overarching themes emerged from the data: 1) Occupational shift from "existing" to "living", 2) The change process is "progressive", and 3) Yoga is "a positive thing I do in my life". Figure 2 illustrates each of the three themes along with subthemes. Quotes were used to illustrate each of the themes. Pseudonym initials were used to represent each participant.
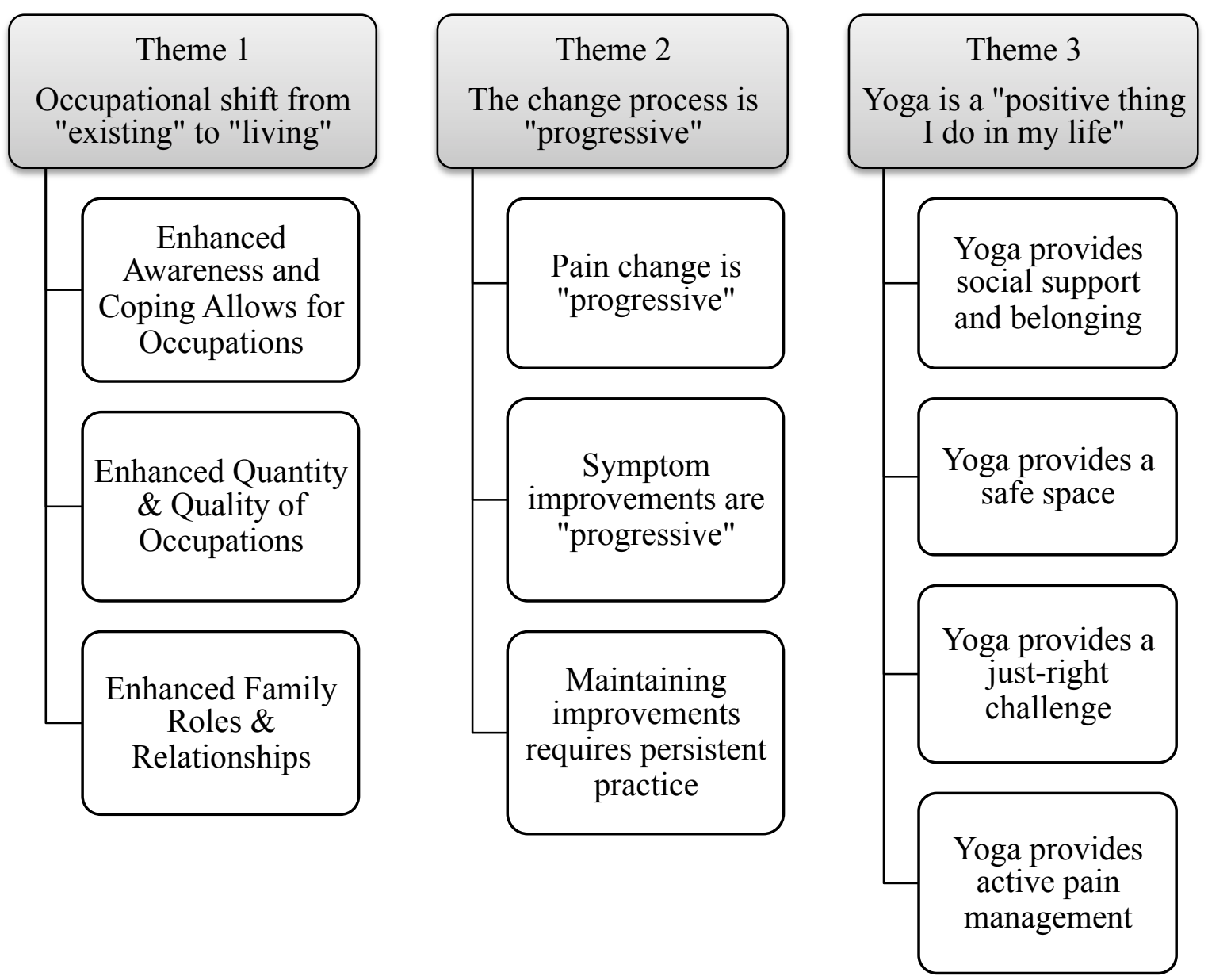

Figure 2. Themes and sub-themes of qualitative findings.

\section{Theme 1: Occupational Shift from "existing" to "living"}

Overall, participants described a shift in their occupational engagement before and after yoga from merely "existing" to "living". Before yoga, participants indicated that they were merely "existing" - their lifestyle was isolated, sedentary, and controlled by their pain. After 
yoga, they described that they were "living" - their lifestyle was rich with occupational engagement, despite their pain. For example, RS reported she often did not get dressed or leave the house prior to yoga: "I'd stay in my...nightgown all day... and then go to bed and I'd wake up in my nightgown." Now, after attending yoga, RS states, "I get dressed. I can comb my hair...I can get out instead of staying in the house all day...I feel like I'm living. Instead of before, I felt like I was just existing." MR also describes a shift from being nearly bed-ridden prior to yoga to participating in a variety of occupations: “I couldn't even get out of bed. It was hard for me to get out of bed to go to the bathroom... Now look at me! I'm walking around, cutting the grass, doing a lot of things." DM describes that her occupational shift was due to feeling more in control of her pain: "It was just like a fight to have to go anywhere because I didn't feel good... it felt like the pain was taking more and more control." After attending yoga, DM states: "I'm involved again with people and not sitting at home maybe feeling sorry for myself...I've been able to take more control over my situation."

Three subthemes emerged that specify the shift in occupational engagement described in Theme 1:1) Enhanced Awareness and Coping Allows for Occupations, 2) Enhanced Quantity and Quality of Occupations, and 3) Enhanced Family Roles and Relationships.

\section{Enhanced Awareness and Coping Allows for Occupation}

Participants expressed that yoga has helped them identify what they are feeling, physically and emotionally, related to pain, and then use yogic coping strategies to manage pain symptoms. SJ describes how increased body awareness helps her keep track of her pain level and appropriately grade activities: "Yoga has a way of being more in tune with your body and you know when to call it quits...when to keep going and when to kind of pull back." This increase in 
awareness of pain and ability to cope with pain allowed participants to successfully engage in occupations.

In addition to increased awareness, participants described using yoga techniques (i.e. postures, breathing, and meditation) in their daily life to cope with pain and engage in occupations. MM describes the physical pain she experiences at work: "I'm not sure I would be able to be working 8 hours a day on my feet if I wasn't taking yoga... it's really excruciating some days" and how she uses yoga postures to cope with her physical pain: "I'll be at the computer or register and I'll bend down and do a forward [fold]...I find that when my back is hurting or my neck is hurting, then some of the yoga moves that we do help it." Many participants described using yogic breathing to manage stress and emotions during social interactions. PB describes using breathing during a social interaction with her son: "When I'm around my son, he stresses me out... I'll get away from him and do some breathing exercises and then come back and I'm better able to handle the situation...I think if I'm relaxed then my pain is better." Other participants used meditation in the form of mantras, or positive self-talk, to help clear their mind and focus on the occupations. MM describes using the following mantra to prepare for sleep: "Put away all of the past and what's happened today...you've worried about that and you don't have to worry about that anymore... so that's what I try to do at night...I think it calms my mind because my mind can be going in 10 different directions."

\section{Enhanced Quantity and Quality of Occupations}

Given yogic coping strategies to manage pain, participants expressed increased quantity of occupations or "doing more" activities on a daily/weekly basis. Many times, participants attributed increased quantity of occupations to having more energy due to yoga. MM stated: "It's 
probably easier to finish any kind of job that I start because I do feel like I have more energy than I did before yoga."

In conjunction with increased quantity, participants articulated increased quality of occupations or "enjoying" activities. SJ described increased quantity and quality when spending time with her daughter: "It's definitely allowed me to be more active with my daughter...before, we wouldn't go to things where I had to walk around very much. Where now, we go to, ya know, museums, zoo, that type of thing... just really being able to go to more things and enjoying it and not me having to struggle through it...it's definitely a happier outing." Quality also included feelings of increased ease, confidence, independence, and control when completing occupations. EH greatly valued completing all of her household chores and expressed that the task was easier on "yoga days":

It makes it a lot easier on yoga days, especially to do things that are difficult for my body like scrubbing the shower floor...I can tell, definitely tell, a difference between doing the same chore on a non-yoga day when I come on all stiff, and then on a yoga day where it's just much easier. It's kind of amazing.

MM described a shift from fear to confidence when riding her bike and increased satisfaction that she was able to participate in this activity with friends:

I think during this time [prior to yoga] I wasn't even doing it because I had such a fear of falling off of a bike... Now I have a lot more confidence in myself that I could do it and I am a lot more satisfied because it's no fun having a group of friends go do something that you can't do or that you're afraid to do. You just have to get out of your comfort zone and do it and if you fall, you fall.

AG and RP described increased independence and control with showering and grocery shopping, respectively:

I don't have to wait for someone to come and have to schedule a shower. If I want to take a shower in the morning, I can go take a shower...Just doing it whenever you want to...I don't have to have someone around to help me do it, so that makes a big difference. 
I like to pick out my own food... when my daughter go grocery shopping...she don't get the same things I get. I get some things that are brand name and some things that are generic...I just like grocery shopping by myself...I can go and I can hold on to the cart and walk around and do my grocery shopping and I like that.

\section{Enhanced Family Roles and Relationships}

Participants also described a shift in their family roles and relationships. Prior to yoga, participants were not spending time with their families or engaging in the activities associated with their family roles. CM described his relationship with his grandchildren prior to yoga: "Before we never used to see them because I didn't feel like I could do nothing...I never used to play with them...My grandkids used to talk to me, they'd say, 'Just go in the other room. Just go in the other room. C'mon, grandpa is mad.' " After yoga, participants described increased time spent with family and improved ability to engage with family members. CM described the difference after participating in yoga: "Now we are more active. Now they go, 'Hi grandpa, how you doing?' and I talk to them...they know I'm happier than before.” AG also described her ability to play with and care of her granddaughter after yoga: "I know it makes a difference having that strength...I can get down on the floor and play with her because I know I can get back up by myself, so it makes it fun to be able to do that."

Additionally, participants felt like less of a burden and able to give back to family members and friends after participating in yoga. AG states: "I was able to start like just lightly mopping the floors and vacuuming and sweeping and dishes...it makes me feel productive and I'm helping them to keep up the house...I don't feel like I'm a burden on them and that they have to do everything." YW explained the joy of being able to help a friend again: "I love to help people, and I haven't been able to do none of that... now at least I try...my friend, she needs help because she's disabled really bad, so I go over there and I talk to her...I could lift a little bit. I'll pick up for her. Do things for her." Lastly, NR describes a change in his desire to take care of 
his wife after yoga: "My wife is in nursing home...before I didn't care about it. Now...my wife calls me and I'm there for her... I come and take her out to eat or something like that."

\section{Theme 2: The Change Process is "progressive"}

Participants spoke of the temporal element of change. They indicated that it took time to notice the benefits of yoga - it did not happen instantaneously - however, they expected to continue seeing improvements into the future. LS states: "It's just progressive and it's so slow...I still have a little trouble bending...I anticipate more things, more strength, and more flexibility." Three subthemes emerged: 1) pain change is "progressive", 2) symptom improvements are "progressive", and 3) maintaining improvements requires persistent practice.

\section{Pain Change is "progressive"}

Many participants indicated that when they began yoga it was painful and difficult, both physically and mentally. However, as participants continued to attend yoga, the pain subsided and they started to notice improvements. RP stated: "It was hard at first...I couldn't do the bending or the stretching or the relaxing...I'm able to do all that now!" JC described that in the beginning yoga was painful: "It was like making it worse." Then, as time went on she began to notice a change and her persistence paid off: "I started just slowly seeing that it does change it...You might be hurting for the first two or three weeks and regretting it... but if you stick it out... you'll start to notice."

\section{Symptom Improvements are "progressive"}

Participants also noted that the benefits of yoga and the changes in their pain symptoms came in a particular order. First, participants noted physical changes in their body and level of pain. Then, they noticed changes to emotional and mental health. Finally, changes to occupations and routines occurred last. SJ describes noticing physical changes before mental changes: "I 
noticed a difference in my body. I think physically I noticed it sooner. Mentally was definitely towards the end for me [post 8-week intervention]." She further explains why the mental change might have taken longer: "So many of us have tried so many things, so when you go into something skeptical...the mental part definitely takes a lot longer to get there because you're still set in the thought process of... it's not gonna work." JC described the timeline of noticing physical changes first and then changes to occupations and routines: "I did notice like within the first 2 months or 3 months...I noticed that I started sitting up straighter...then other things started coming a year after and I started to see a lot of things... like walking long distances, being able to hang out with everybody longer cause usually I was always 5 minutes, 10 minutes and then out, so I could stay longer and hang out. I can go to the store and stay longer, just different things."

\section{Maintaining Improvements Requires Persistent Practice}

Many participants noted the importance of a consistent yoga practice to continue seeing the benefits of decreased pain and increased strength and flexibility, as well as, to maintain health given their current conditions. SJ describes the need to continue coming to yoga to maintain a low pain level: "When I did stop going [to yoga] temporarily...the spasms came right back...I can literally feel the difference without going to 2 classes for the week...your body just goes, it wants to go right back...It's that constant... doing it... I think that has been a big difference too of why it keeps me going is the difference that I notice when I don't go.” Furthermore, EH described the importance of attending yoga to maintain her optimal health and functioning despite a degenerative disease: "My condition is going to get worse. It's not likely to stay this way, and it's certainly not likely to get better, so yoga's my next best ally, I would say, in keeping my body as functional as it can be at any stage." 


\section{Theme 3: Yoga is a "positive thing I do in my life"}

All participants described yoga as a meaningful activity in their lives that they looked forward to attending. MM states: "I was staying at home and it was real easy to become a hermit and just stay there, and to have something like yoga to look forward to and come to...has helped a lot." EH describes that yoga has become an positive activity she tells other people about: "I always tell everybody you would love it!... It just gives me something to say about what positive thing I do in my life." Four subthemes emerged related to why yoga became a meaningful activity: 1) yoga provides social support and belonging, 2) yoga provides a safe space, 3) yoga provides a just-right challenge, and 4) yoga provides active pain management.

\section{Yoga Provides Social Support and Belonging}

Participants indicated that yoga and the people in yoga provided a support system and encouragement on days that were difficult due to pain. AG stated: "I know we have the support from each other... it's nice that we can all encourage each other and help someone who's feeling down." RP elaborated on the importance of having a group of people who were going through a similar experience: "I like being around other people who got pain just like me, so they kind of know what I'm going through...They can do this and their hurting...so why can't I try." Friendships were created at yoga and some even extended outside of the classroom into daily life. MM explained: "I have the one friend that I said we kind of took each other to the doctor's things that had to be done. Now I go to church with her. We've had lunches together. She's invited me for Thanksgiving because she knows my family's not around, so I wouldn't have met her if I...hadn't come here." 


\section{Yoga Provides a Safe Space}

Participants described yoga at the Pain Clinic as a safe space where they could be themselves and take care of themselves. LS stated: "This is a special group of people...we can just be whatever we want to be when we get here. Nobody care what we look like... it's a good place." Others described yoga at the Pain Clinic as a therapeutic space where they were comfortable resting and relaxing. SJ experienced daily stress due to caring for her family and described yoga as a place where she could rest and relax: "I can be by myself and not have to

think or worry about anything for that amount of time that I'm there." Lastly, RP described yoga at the Pain Clinic as a place for laughter and fun: "We laugh and tell little stories or jokes or talk about our life sometimes, and the funny things that happen in it... so that's fun!... I wasn't doing a lot of laughing or anything, but I'm doing it now!"

\section{Yoga Provides a Just-right Challenge}

Participants noted that yoga was challenging, but also individualized and modifiable to their needs. PB describes the challenge and the ability to modify: "Sometimes it kind of tests me a little bit with some of the poses... but I still try...I can start a little bit lower and work my way up." Participants often attributed the individualized quality of yoga to the instructor's ability to affectively modify the practice to their needs, providing them with the just-right challenge. AG elaborates on how the instructor modifies poses during class: "She [the instructor] was able to modify how I could stretch to help my body... I wasn't doing everything everybody else was doing... everybody is going at their own pace". SJ describes the benefit of a knowledgeable instructor: "There is somebody there that is targeting things that we need, and also being aware of letting us know when we shouldn't do this...just being very aware of your body...yoga that's more medical-based, where they are in-tuned with what is going on with you is great!" Given 
these challenges and modifications, participants described feelings of accomplishment and a newfound confidence in abilities to set and achieve goals:

It just has a feeling of accomplishment that you can do some of the things like, oh, I'm getting closer to my toes!... and just making me realize that I can do that and I can make those kind of goals...that's what yoga is teaching me (MM).

\section{Yoga Provides Active Pain Management}

Participants distinguished yoga as actively engaging in their pain management, which was different from other more passive methods (e.g. pain medications) or more invasive therapies (e.g. exercise equipment and manual therapies) previously tried. JC described the difference between yoga and taking pain medication: "You do the stretch and you breathe the pain through it...instead of just laying there being in pain and pop a pill and I mean that's way different...[in yoga] the pain ends up gradually going away more and more.” By actively engaging in yoga, participants were "in charge" or in control of their body and their pain management. EH described how yoga was different from manual therapies: "With physical therapy...it was painful doing it... There seemed to not be a rhyme nor reason of why am I doing this to accomplish this... [in yoga] the movements are less intrusive...you're in charge of every movement that you make. If it hurts, don't do it, is always the word." AG described how yoga was different from using equipment at a gym: "I don't have to rely on machines or equipment to do this. It's just I'm using my body...controlling my body more, not letting it have control.”

\subsection{Discussion}

The purpose of this study was to examine participants' perceived impact of long-term involvement in a community-based group yoga class on their occupations and related pain symptoms. Quantitative results suggest that continued, long-term involvement in yoga can significantly improve occupational performance and satisfaction. Qualitative results provide 
insights into these occupational improvements, as well as, participants' perceptions on the process of change and the components of yoga that likely promote change.

\section{Occupational Improvements}

Despite a small sample size, statistically and clinically significant improvements were demonstrated in perceived occupational performance and satisfaction, as measured by the COPM. This finding is consistent with the previous RCT that found improvements in occupational performance and satisfaction after the 8-week yoga intervention (Schmid, in review). However, the current study is the first to examine long-term impacts of yoga on occupational performance and satisfaction in people with chronic pain after continued involvement in yoga. These results suggest that continued involvement in yoga may help improve but also sustain occupational health and well-being in people experiencing chronic pain.

Interestingly, occupational satisfaction scores on the COPM more than doubled (154\%) compared to occupational performance scores that improved by about half (64\%). This may be explained by yogic philosophy that emphasizes less attachment to the past and more contentment in the present moment. Previous research suggests that yoga may increase pain acceptance and frequency of positive emotions (Curtis, Osadchuk, \& Katz, 2011; Shapiro \& Cline, 2004), implying a shift in cognitive and emotional processing. This shift in cognitive and emotional processing may be part of why satisfaction drastically improved compared to performance.

Qualitative findings confirmed and strengthen quantitative results by also indicating improvements in occupation, including increased quantity and quality of a variety of occupations due to yoga. Participants indicated increased energy, ease, and confidence to complete occupations, as well as, increased independence and control when performing activities. A qualitative study looking at perceived outcomes of yoga for people with stroke found similar 
improvements related to occupations including, less effort, improved confidence, and improved quantity and quality of occupations (Atler et al., 2017). Participants in the current study also noticed improvements to fulfilling life roles, including family member and friend. Participants stated they felt like less of a burden because they were able to spend more time with family and friends and give back by completing chores or being of service. These improvements to occupations are important because people with chronic pain report low quality of life due to decreased independence, loss of control, limited social involvement, and inability to complete activities (Fisher et al., 2007). Participants in the current study attributed occupational improvements to continued involvement in yoga, and specifically, the ability to manage pain during these occupations by using yoga techniques.

\section{Yoga to Manage Pain in Daily Life}

Previous research on patient expectations for pain rehabilitations programs, including complementary and integrative therapies, indicate that patients expect to receive pain management coping strategies to implement in daily life (Eaves et al., 2015; Larsson et al., 2016). Participants in the current study reported that yoga increased awareness of pain symptoms, both physical and emotional, and provided yoga techniques to cope with pain during daily life. They described using physical postures to relieve pain, breathing to manage stress, and meditation to clear their mind. Another qualitative study examining the perceived impact of a 9week yoga intervention for people with chronic neck pain, found similar increases in body awareness and use of yoga techniques to cope with pain in daily life (Cramer et al., 2013b). However, after the 9-week intervention, not all participants found yoga to be beneficial or applicable to managing pain. This discrepancy highlights that yoga may be beneficial for some, but not for all people experiencing chronic pain. Nevertheless, the results of the current study 
indicate that yoga techniques can be integrated into daily life to help people successfully cope with chronic pain and engage in occupations.

\section{Progression of Health Changes}

Some participants indicated that positive changes in pain symptoms occurred in a particular order or progression: First, physical changes (i.e. strength, flexibility, and pain level), second, emotional and mental changes (i.e. moods and attitudes), and third, occupational changes (i.e. performance and participation in everyday activities). Specifically, participants noticed physical changes in the first 2-3 weeks, mental and emotional changes around 8 weeks, and occupational changes up to 3 months after beginning yoga. This progression may be indicative of the dosage of yoga needed to achieve certain outcomes. Additionally, participants agreed that consistent practice of yoga was critical to sustaining positive changes. In a qualitative study examining complementary and alterative treatments for chronic pain that included yoga, participants also expressed the importance of continued practice in yoga classes and home programs to maintain results (Eaves et al., 2015). Currently, the optimal dosage of yoga is unknown, and the literature is controversial as to whether short-term or long-term interventions yield stronger results (Bussing et al., 2012). Therefore, dosage should continue to be addressed in future studies.

\section{Characteristics of Yoga}

Lastly, participants described certain characteristics of yoga that contributed to yoga becoming a meaningful activity and an effective form of pain management. All participants indicated that yoga led to the development of a socially supportive environment where they could connect with people experiencing a similar situation. Previous qualitative studies on yoga and pain management interventions confirm the importance of social connection and support 
with a group of people experiencing a similar diagnosis (Crowe, Van Puymbroeck, \& Schmid, 2016; Danhauer et al., 2008; Larsson et al., 2016; Van Puymbroeck et al., 2013). Additionally, participants described yoga as a therapeutic place to relax and cope with the stressors of life. This is a common benefit of yoga for people with or without an illness, but seems particularly beneficial for people experiencing chronic illness that impacts all facets of life.

Additionally, participants noted the importance of yoga being individualized to their needs, and often praised the yoga instructor's ability to modify the pose to meet their needs and provide an appropriate challenge. It is important to note that the yoga instructor in this study was also an occupational therapist, and occupational therapists are specifically trained to assess a person's needs and create a just-right challenge (American Occupational Therapy Association, 2014; Yerxa, 1998). In this way, occupational therapists may be uniquely suited to administer and modify yoga interventions for people with chronic pain and other medical diagnoses.

Lastly, previous research has described yoga as an "action-oriented coping mechanism" and an "active self-help strategy" (Cramer et al., 2013b; Crowe et al., 2016). Participants in this study shared a similar sentiment that yoga provided a means to actively engage in pain management. Other popular treatments for chronic pain are typically passive and/or invasive (i.e. pain medication, manual therapies, or general exercise). Participants appreciated that yoga provided an active way to manage pain, while allowing them to be in control of their movements. Active engagement seems to be a unique and vital characteristic of yoga for pain management.

\section{Study Limitations and Future Directions}

There are several limitations to this mixed methods study. First, the sample was small, and results cannot be generalized. Second, the sample consisted of people choosing to continue practicing yoga for chronic pain, thus may represent a highly motivated and yoga-bias group of 
people. Furthermore, the difference between those who chose to continue attending yoga postintervention and those that chose not to is unknown. Therefore, further research exploring the experience of those whom did not continue practicing yoga is important. Third, participants spoke of other things they did to manage pain including general exercise, walking, tai chi, and taking pain medications. Researchers did not control for these variables, therefore, outcomes perceived by participants may have been influenced by other factors. Lastly, a graduate student who was unfamiliar to the participants conducted interviews; therefore, a social desirability bias may have existed, as participants might have shared what the interviewer wanted to hear. Despite these limitations, this study produced important long-term findings from the perspective of people with chronic pain participating in yoga for approximately 2 years. Findings included occupational gains, the progressive nature of change, and the unique experience of group yoga for chronic pain.

As far as we know, this is first and only study to examine the long-term impact of continued involvement in a community-based group yoga class for people with chronic pain. Future research should continue to examine the long-term outcomes of involvement in group yoga for people with chronic pain, specifically, by using a randomized control design and quantitative outcomes measures to control for extraneous variables and increase efficacy of results. Additionally, research should continue to compare short-term and long-term yoga interventions to determine optimal dosage of yoga for chronic pain outcomes. This study only examined people who had chosen to continue participating in this group yoga class. To obtain a fuller picture of the accessibility of yoga, it would be beneficial to interview the people who chose to stop attending yoga. Lastly, researchers could conduct a cost-benefit analysis of this 
community-based yoga program to determine a future plan of action on how to continue and improve the program.

\section{Conclusion}

In this study, adults with chronic pain demonstrated improved occupational performance and satisfaction after 2 years of attending a community-based group yoga class. Participants reported improved ability to manage pain in daily life, increased quantity and quality of occupations, and enriched social relationships due to yoga. Participants also indicated that positive changes to pain symptoms followed a progression (e.g., physical to mental/emotional to occupational) and required persistent practice. Lastly, participants described four vital components of yoga: 1) it provides social support, 2) it creates a safe space, 3) it can be individualized to the person's needs, and 4) it is an active form pain management. These results suggest that continued involvement in group yoga may maintain occupational health and wellbeing in people with chronic pain. Therefore, occupational therapists may consider yoga as a tool to promote occupational health in people with chronic pain. 


\section{CHAPTER 5: CONCLUSION}

\subsection{Implications to Occupational Therapy Practice}

People with chronic pain experience impairments to their physical, emotional, mental, social, and occupational health (Fisher et al., 2007). Given the current ineffective biomedical and high-cost treatments for chronic pain, it is important to research more holistic, low-cost interventions to effectively manage chronic pain symptoms (National Institute of Health, 2016). This study offers support that yoga provides people with tools to successfully manage pain and increase engagement in meaningful occupations. This study also indicates that people in this sample with chronic pain appreciated that yoga can be individualized to their needs and adjusted to provide the appropriate challenge. Occupational therapists are exceptionally skilled to assess a person's needs and individualize a task to provide the just-right challenge. Additionally, the American Occupational Therapy Association (AOTA) acknowledges yoga as a complementary integrative therapy (CIT) that can prepare and enhance participation and engagement in occupations. Therefore, occupational therapists may be uniquely suited to administer individual and group yoga interventions for people with chronic pain. Lastly, this study supports community-based group yoga as a form of pain rehabilitation. Yoga for pain rehabilitation is not currently funded by insurance in the United States, so occupational therapists need to advocate for community organizations and student-run clinics to provide group yoga interventions. 


\section{REFERENCES}

Aegler, B., \& Satink, T. (2009). Performing occupations under pain: The experience of persons with chronic pain. Scandinavian Journal of Occupational Therapy, 16(1), 49-56.

American Occupational Therapy Association. (2014). Occupational Therapy Practice

Framework: Domain and process. American Journal of Occupational Therapy, 68(Suppl 1), S1-S48.

American Occupational Therapy Association. (2016). Occupational Therapy and Complementary Health Approaches and Integrative Health. American Journal of Occupational Therapy, 71.

Atler, K. E., Van Puymbroeck, M., Portz, J. D., \& Schmid, A. A. (2017). Participant-perceived outcomes of merging yoga and occupational therapy: Self-management intervention for people post stroke. British Journal of Occupational Therapy, 80(5), 294-301.

doi: $10.1177 / 0308022617690536$

Bussing, A., Ostermann, T., Ludtke, R., \& Michalsen, A. (2012). Effects of yoga interventions on pain and pain-associated disability: a meta-analysis. J Pain, 13(1), 1-9. doi:10.1016/j.jpain.2011.10.001

Carpenter, L., Baker, G. A., \& Tyldesley, B. (2001). The use of the Canadian Occupational Performance Measures as an outcome of a Pain Management Program. Canadian Journal of Occupational Therapy, 68(1), 16-22.

Carswell, A., McColl, M. A., Baptiste, S., Law, M., Polatajko, H., \& Pollock, N. (2004). The Canadian Occupational Performance Measure: A research and clinical literature review. Canadian Journal of Occupational Therapy, 71(4), 210-222. 
Cramer, H., Lauche, R., Haller, H., \& Dobos, G. (2013a). A systematic review and meta-analysis of yoga for low back pain. Clinical Pain Journal, 29(5), 450-460.

Cramer, H., Lauche, R., Haller, H., Langhorst, J., Dobos, G., \& Berger, B. (2013b). "I'm more in balance": a qualitative study of yoga for patients with chronic neck pain. Journal of Alternative and Complementary Medicine, 19(6), 536-542. doi:10.1089/acm.2011.0885

Creswell, J. W. (2013). Qualitative Inquiry \& Research Design: Choosing Among Five Approaches (3rd ed.). Thousand Oaks, CA: SAGE Publications, Inc.

Crowe, B. M., Van Puymbroeck, M., \& Schmid, A. A. (2016). Yoga as coping: A conceptual framework for meaningful participation in yoga. International Journal of Yoga Therapy, $26,123-129$.

Curtis, K., Osadchuk, A., \& Katz, J. (2011). An eight-week yoga intervention is associated with improvements in pain, psychological functioning and mindfulness, and changes in cortisol levels in women with fibromyalgia. Journal of Pain Research, 4, 189-201. doi:10.2147/JPR.S22761

Dagenais, S., Caro, J., \& Haldeman, S. (2008). A systematic review of low back pain cost of illness studies in the United States and internationally. Spine Journal, 8(1), 8-20. doi:10.1016/j.spinee.2007.10.005

Danhauer, S. C., Tooze, J. A., Farmer, D. F., Campbell, C. R., McQuellon, R. P., Barrett, R., \& Miller, B. E. (2008). Restorative yoga for women with ovarian or breast cancer. Findings from a pilot study. Journal of Society for Integrative Oncology, 6(2), 47-58. doi:10.2310/7200.2008.0008 
Davis, J. H. (2017). Trump Declares Opioid Crisis a 'Health Emergency' but Requests No Funds. The New York Times. Retrieved from http://www.nytimes.com/2017/10/26/us/politics/trump-opioid-crisis.html

Eaves, E. R., Sherman, K. J., Ritenbaugh, C., Hsu, C., Nichter, M., Turner, J. A., \& Cherkin, D. C. (2015). A qualitative study of changes in expectations over time among patients with chronic low back pain seeking four CAM therapies. BMC Complementary and Alternative Med, 15, 12. doi:10.1186/s12906-015-0531-9

Engel, G. L. (1977). The need for a new medical model - A challenge for biomedicine. Science, 196(4286), 129-136.

Engel, J. M. (2001). Occupational therapy practive guielines for chronic pain. Retrieved from Bethesda, MD:

Fayaz, A., Croft, P., Langford, R. M., Donaldson, L. J., \& Jones, G. T. (2016). Prevalence of chronic pain in the UK: a systematic review and meta-analysis of population studies. British Medical Journal Open, 6(6), e010364. doi:10.1136/bmjopen-2015-010364

Fishbain, D. A., Cutler, R., Rosomoff, H., \& Rosomoff, R. S. (1997). Chronic pain-associated depression: antecedent or consequence of chronic pain. The Clinical Journal of Pain, 13(2), 116-137.

Fisher, G. S., Emerson, L., Firpo, C., Ptak, J., Wonn, J., \& Bartolacci, G. (2007). Chronic pain and occupation: An exploration of the lived experience. American Journal of Occupational Therapy, 61, 290-302.

Global Industry Analysts, I. (2011). Global Pain Management Report. Retrieved from http://www.prweb.com/releases/2011/1/prweb8052240.htm 
Guzman, J., Esmail, R., Karjalinen, K., Malmivaara, A., Irvin, E., \& Bombardier, C. (2006). Multidisciplinary bio-psycho-social rehabilitation for chronic low-back pain (review). The Cochrane Library(1), 1-30.

Hoffman, A. O. (n.d.). Living Life to Its Fullest: Managing Chronic Pain with Occupational Therapy. Retrieved from http://www.aota.org/about-occupationaltherapy/professionals/hw/articles/chronic-pain.aspx

Jackson, T. P., \& Stabile, V. S. (2014). The Global Burden. American Society of Anesthesiologists, 78(6), 24-27.

Kamper, S. J., Apeldoorn, A. T., Chiarotto, A., Smeets, R. J., Ostelo, R. W., Guzman, J., \& van Tulder, M. W. (2015). Multidisciplinary biopsychosocial rehabilitation for chronic low back pain: Cochrane systematic review and meta-analysis. British Medical Journal, 350, 1-11. doi:10.1136/bmj.h444

Larsson, B., Gard, G., Karlsson, L., \& Persson, A. L. (2016). Patient expectations for a multimodal pain rehabilitation programme: active participation and coping skills. A qualitative study. Disability and Rehabilitation, 38(21), 2135-2143. doi:10.3109/09638288.2015.1114154

Law, M., Baptiste, S., Carswell, A., McColl, M. A., Polatajko, H., \& Pollock, N. (1998). Canadian Occupational Performance Measure (3rd ed.). Toronto, On: CAOT Publications ACE.

Law, M., Baptiste, S., McColl, M. A., Opzoomer, A., Polatajko, H., \& Pollock, N. (1990). The Canadian Occupational Performance Measure: An outcome measure for occupational therapy. Canadian Journal of Occupational Therapy, 57(2), 82-87. 
Mailoo, V. J. (2005). Yoga: an Ancient Occupational Therapy? British Journal of Occupational Therapy, 66(12), 574-577.

Marin, T. J., Van Eerd, D., Irvin, E., Couban, R., Koes, B. W., Malmivaara, A., . . Kamper, S. J. (2017). Multidisciplinary biopsychosocial rehabilitation for subacute low back pain. Cochrane Database Syst Rev, 6, CD002193. doi:10.1002/14651858.CD002193.pub2

McCaffrey, M. (2000). Nursing Management of the Patient with Pain. Philadelphia: Lippincott.

McCaffrey, R., Frock, T. L., \& Garguilo, H. (2003). Understanding chronic pain and the mindbody connection. Holistic Nursing Practice, 17(6), 281-287.

Melzack, R. (1982). Recent concepts of pain. Journal of medicine, 13(3), 147-160.

Merriam, S. (2009). Qualitative Research: A Guide to Design and Implementation. San Francisco, CA: Jossey-Bass.

Moseley, G. L., \& Butler, D. S. (2015). Fifteen Years of Explaining Pain: The Past, Present, and Future. J Pain, 16(9), 807-813. doi:10.1016/j.jpain.2015.05.005

National Institute of Health. (2016). National Pain Strategy: A comprehensive population healthlevel strategy for pain.

Navratilova, E., Morimura, K., Xie, J. Y., Atcherley, C. W., Ossipov, M. H., \& Porreca, F. (2016). Positive emotions and brain reward circuits in chronic pain. Journal of Comparative Neurology, 524(8), 1646-1652. doi:10.1002/cne.23968

Nayak, N. N., \& Shankar, K. (2004). Yoga: A therapeutic approach. Physical Medicine and Rehabilitation Clinics North America, 15(4), 783-798. doi:10.1016/j.pmr.2004.04.004

Persson, E., Lexell, J., Rivano-Fischer, M., \& Eklund, M. (2013). Everyday occupational problems perceived by participants in a pain rehabilitation programme. Scandinavian Journal of Occupational Therapy, 20(4), 306-314. 
Persson, E., Lexell, J., Rivano-Fischer, M., \& Eklund, M. (2014). Occupational performance and factors associated with outcomes in patients participating in a musculoskeletal pain rehabilitation programme. Journal of Rehabilitation Medicine, 46(6), 546-552. doi:10.2340/16501977-1810

Persson, E., Rivano-Fischer, M., \& Eklund, M. (2004). Evaluation of changes in occupational performance among patients in a pain management program. Journal of Rehabilitation Medicine, 36(2), 85-91. doi:10.1080/16501970310019142

Phillips, C. J. (2009). The cost and burden of chronic pain. The Economist, 3(1), 2-5.

Posadzki, P., Ernst, E., Terry, R., \& Lee, M. S. (2011). Is yoga effective for pain? A systematic review of randomized clinical trials. Complementary Therapy in Medicine, 19(5), 281287. doi:10.1016/j.ctim.2011.07.004

Rochman, D. L. (2014). Occupational therapy and pain rehabilitation fact sheet. Retrieved from Bethesda, MD:

Schmid, A. A. (in review). Yoga for people with chronic pain in a community-based setting: A feasibility and pilot RCT. Complementary Therapies in Medicine.

Schmid, A. A., Portz, J., Fruhauf, C. A., Van Puymbroeck, M., Bair, M., Chop, C., \& Grimm, L. A. (2018, April). Yoga improves occupational performance, pain-related disability, and activities of daily living for people with chronic pain. Paper presented at the Presentation in a Scientific Panel at the American Occupational Therapy Association Annual Conference, Salt Lake City, UT.

Sewell, L., \& Singh, S. J. (2001). The Canadian occupational performance measure: Is it a reliable measure in clients with chronic obstructive pulmonary disease? The British Journal of Occupational Therapy, 64(6), 305-310. 
Shapiro, D., \& Cline, K. (2004). Mood changes associated with Iyengar yoga practices: a pilot study. International Journal of Yoga Therapy, 14, 35-44.

Stevens-Ratchford, R., \& Lookingbill, J. (2004). Living well with arthritis: A phenomenological study of leisure occupations. Activities, Adaptation \& Aging, 28(2), 35-55.

Van Puymbroeck, M., Burk, B. N., Shinew, K. J., Kuhlenschmidt, M. C., \& Schmid, A. A. (2013). Perceived benefit from yoga among breast cancer survivors. American Journal of Health Promotion, 27(5), 308-315.

Walsh, D. A., Kelly, S. J., Johnson, P. S., Rajkumar, S., \& Bennetts, K. (2003a). Performance problems of patient with chronic low-back pain and the measurement of patient-centered outcome. SPINE, 29(1), 87-93.

Walsh, D. A., Kelly, S. J., Johnson, P. S., Rajkumar, S., \& Bennetts, K. (2003b). Performance problems of patients with chronic low-back pain and the measurement of patient-centered outcomes. SPINE, 29(1), 87-93.

Willis Boslego, L. A., Munterfering Phillips, C. E., Atler, K. E., Tracy, B. L., Van Puymbroeck, M., \& Schmid, A. A. (2017a). Impact of yoga on balance, balance confidence and occupational performance for adults with diabetic peripheral neuropathy: A pilot study. British Journal of Occupational Therapy, 80(3), 155-162. doi: $10.1177 / 0308022616680364$

Willis Boslego, L. A., Munterfering Phillips, C. E., Atler, K. E., Tracy, B. L., Van Puymbroeck, M., \& Schmid, A. A. (2017b). Yoga improve occupationsal performance, balance, and balance self-efficacy for people with diabetic neuropathy. British Journal of Occupational Therapy, 80(3), 155-162. 
Wren, A. A., Wright, M. A., Carson, J. W., \& Keefe, F. J. (2011). Yoga for persistent pain: New findings and directions for an ancient practice. Pain, 152(3), 477-480. doi:10.1016/j.pain.2010.11.017

Yerxa, E. J. (1998). Health and the human spirit for occupation. American Journal of Occupational Therapy, 52, 412-418. 


\section{APPENDIX A: INTERVIEW SCRIPT AND QUESTIONS}

“Hi again, my name is Caroline Rose. I'm an occupational therapy graduate student with Dr. Arlene Schmid. First of all, I wanted to thank you for taking the time to talk with me. For my thesis project, I am interested in knowing about your experience participating in yoga for chronic pain. We only have an hour and I have a lot of things I want to ask you and hear about. I might interrupt you at times so that we stay on track. That being said, I am very excited to hear what you have to say! I'll be using this tape recorder to record our conversation so that I can go back and listen to it. That way, I can make sure I don't miss anything. This recording will only be used for research purposes. If there is anything you don't want to be recorded, you can let me know, and I will turn it off. Does that sound good? I'd like to start off my asking you a few general questions about your yoga practice."

Icebreaker questions:

- How long have you been practicing in yoga?

- Has that been since you participated in the yoga intervention with Arlene?

- About how often do you come to the pain clinic for yoga?

- Is that pretty consistent?

General questions about yoga experience

- What's your favorite part of yoga?

- What do you like about yoga?

- Tell me a little bit about your experience with yoga...

- How has participating in yoga impacted your life?

○ Routines? Habits? 
- Since doing yoga, what sorts of changes have you noticed?

○ Physical?

○ Mental?

○ Emotional?

○ Routines?

○ Social?

$\circ$ Health?

- What has led you to continue practicing?

- Do you have a regular home practice? If so, how often?

- How is yoga different from other things you have tried to manage pain?

- How would you describe yoga to other people with chronic pain?

"A while back, right before you started doing yoga for the research study, we ask you to think of 5 activities that were important to you, but also challenging for you to do. You selected these 5 activities. Then, we asked you to rate your ability to complete each activity on a scale from 1 to 10.1 being unable to do and 10 being you can do it easily. How would you rate your ability to do this activity now?"

"Then we asked you to rate your satisfaction with your ability to do each activity. How would you rate your satisfaction with doing this activity now on a scale of 1 to 10 ? 1 being not at all satisfied with your performance and 10 being completely satisfied."

"Now we are going to look at how your performance and satisfaction with each activity has changed since you completed the study. For example, before you started yoga, you rated that doing ___ was a___ out of 10 on the difficulty to perform scale. Then, after doing 
yoga for 8 weeks, you rated as a out of 10 . Now, it's a out of 10. Your satisfaction changed from to to

General question related to COPM:

- I notice that this activity has changed. What do you think has led to this change?

\begin{tabular}{|c|c|c|}
\hline If improved & If maintained & If declined \\
\hline $\begin{array}{l}\text { I notice that your } \\
\text { performance with this } \\
\text { activity has improved. What } \\
\text { has led to this change? }\end{array}$ & $\begin{array}{l}\text { I notice you're your } \\
\text { performance with this } \\
\text { activity has stayed the stay. } \\
\text { Why do you think that is? }\end{array}$ & $\begin{array}{l}\text { I notice that your } \\
\text { performance with this } \\
\text { activity has gone down. } \\
\text { What has led to that } \\
\text { change? }\end{array}$ \\
\hline $\begin{array}{l}\text { I notice that your } \\
\text { satisfaction with this } \\
\text { activity has improved. What } \\
\text { has led to this change? }\end{array}$ & $\begin{array}{l}\text { I notice you're your } \\
\text { satisfaction with this } \\
\text { activity has stayed the } \\
\text { same. Why do you think } \\
\text { that is? }\end{array}$ & $\begin{array}{l}\text { I notice that your } \\
\text { satisfaction with this } \\
\text { activity has gone down. } \\
\text { What has led to that } \\
\text { change? }\end{array}$ \\
\hline $\begin{array}{l}\text { How do you think yoga } \\
\text { may have contributed to this } \\
\text { improvement? }\end{array}$ & $\begin{array}{l}\text { How do you think yoga has } \\
\text { helped you maintain this } \\
\text { improvement? }\end{array}$ & $\begin{array}{l}\text { Are these activities still } \\
\text { important to you? } \\
\text { If not, what is important } \\
\text { now? }\end{array}$ \\
\hline
\end{tabular}

Concluding questions:

- $\quad$ Are these activities still important to you now? 
If not, what is important now?

- Are there other changes in your daily activities that you noticed?

○ What? Where? When? How long?

- Routines? Habits?

- Are you surprised by the changes you have seen?

- Is there anything else you'd like to tell us about your experience doing yoga? 